\title{
Slow Axonal Transport in Acrylamide Neuropathy: Different Abnormalities Produced by Single-dose and Continuous Administration ${ }^{1}$
}

\author{
BRUCE G. GOLD, ${ }^{\star 2}$ JOHN W. GRIFFIN, $\ddagger$ AND DONALD L. PRICE \\ *Neuropathology Laboratory, Department of Environmental Health Sciences, $\ddagger$ Neuromuscular Laboratory, Departments of Neurology \\ and Neuroscience, and $\S$ Neuropathology Laboratory, Departments of Pathology, Neurology, and Neuroscience, The Johns Hopkins \\ University School of Medicine, Baltimore, Maryland 21205
}

\begin{abstract}
Alterations in axonal caliber and neurofilament content have been associated with altered neurofilament transport in several models of neurofibrillary degeneration. Acrylamide intoxication provides a prototype of distal axonal degeneration, the most frequent pattern of axonal pathology in human and experimental neurotoxic injury. Neurofibrillary changes are a variable and often minor aspect of the early pathological changes observed in acrylamide intoxication, and previous studies of slow axonal transport have produced conflicting results. In this study, we have correlated slow axonal transport, specifically neurofilament transport, with structural changes in the sciatic nerve complex of rats exposed to acrylamide.

To study direct toxic effects of acrylamide, young rats were given a single dose of acrylamide $(75 \mathrm{mg} / \mathrm{kg}$, i.p.). A second group received daily injections of acrylamide at a lower dose (30 mg/kg, i.p.) in order to study animals with established acrylamide neuropathy. The slow component of axonal transport was labeled by intraspinal injections of $\left[{ }^{35} \mathrm{~S}\right]$ methionine. Transport of individual slow component polypeptides was compared to profiles obtained from age-matched controls. Similarly intoxicated rats were perfused for morphometric and morphological studies. Results demonstrate that two different abnormalities of the slow component of axonal transport arise at different stages during the development of experimental acrylamide neuropathy. Both patterns of altered transport have structural correlates which reflect the changes in neurofilament transport. Following a single high dose, there was a modest retardation of the leading edge of the slow component. At this time, neurofilaments accumulated in proximal axons with formation of axonal swellings. During chronic administration, when distal axonal degeneration was present, the proportion of neurofilaments in the slow component was markedly reduced, and there was prominent loss
\end{abstract}

Received September 4, 1984; Revised November 26, 1984;

Accepted December 14, 1984

\footnotetext{
${ }^{1}$ We would like to thank Dr. Jeffrey Rosenfeld for helpful discussion and assistance with statistics, Ms. Adelaine Stocks for expert technical assistance, and Mrs. Carla R. Jordan for manuscript preparation. This work was supported by National Institutes of Health Grants NS 07179, NS 10580, NS 15721, and ES 07094 from the United States Public Health Service. J. W. G. is the recipient of Research Career Development Award NS 00450

${ }^{2}$ To whom correspondence should be addressed, at Neuropathology Laboratory, 509 Pathology Bulding, The Johns Hopkins University School of Medicine, 600 North Wolfe Street, Baltimore, MD 21205.
}

of caliber in proximal axons. We suggest that these early changes represent a direct toxic effect of acrylamide on slow transport, whereas the later changes reflect reordering of slow transport as a neuronal response to toxin-induced axonal injury. This latter effect is of sufficient magnitude to obscure the acrylamide-induced retardation of slow transport.

Progressive degeneration of the distal regions of long axons (dying back) is the predominant pathological change occurring in a variety of human and experimental disorders produced by heritable factors, metabolic abnormalities, and toxins (Cavanagh, 1964; Spencer and Schaumburg, 1976). The roles of axonal transport abnormalities in the pathogenesis of distal axorial degeneration and their predegenerative pathological changes have been areas of intense study. Acrylamide neurotoxicity has provided a prototypical model of toxininduced distal axonal degeneration (Fullerton and Barnes, 1966). Although controversy still exists, it now seems clear that acrylamide administration produces abnormalities of the fast bidirectional transport systems, particularly within distal regions of the axon (Sahenk and Mendell, 1981; Jakobsen and Sidenius, 1983; Miller et al., 1983).

Studies of slow axonal transport have produced conflicting results. The initial report of a major impairment in slow transport (Pleasure et al., 1969) has not been confirmed (Bradley and Williams, 1973). Recently, Sidenius and Jakobsen (1983) reported that, in animals with established acrylamide neuropathy, there is a decreased amount of radiolabel within slow component a (SCa), which includes the neurofilament triplet proteins (Lasek and Hoffman, 1976). However, slow component $b$ (SCb), consisting mostly of tubulin and actin in the sciatic nerve (Hoffman and Lasek, 1980), appeared normal. It should be emphasized that, with one exception (Miller et al., 1983), all of the axonal transport studies were performed following prolonged periods of exposure to acrylamide and involved animals with weakness or paralysis in the hindlimbs. Thus, the presence of axonal degeneration may complicate the interpretation of these studies.

To differentiate early, presumably direct, effects of acrylamide on slow axonal transport from later changes arising secondary to chronic neuropathy, we examined the effects of a single injection of acrylamide on slow transport and compared these findings with the effects of continuous administration for a period sufficient to induce distal axonal degeneration. The distribution along the nerve of individual labeled slow component proteins was correlated with morphometric studies of axonal caliber and neurofilament content. Morphological studies were focused on regions of nerve fibers nearest neuronal cell bodies (i.e., the proximal ventral root and dorsal root near the dorsal root ganglia), since any alteration in the balance between delivery of neurofilaments from the cell body and their 

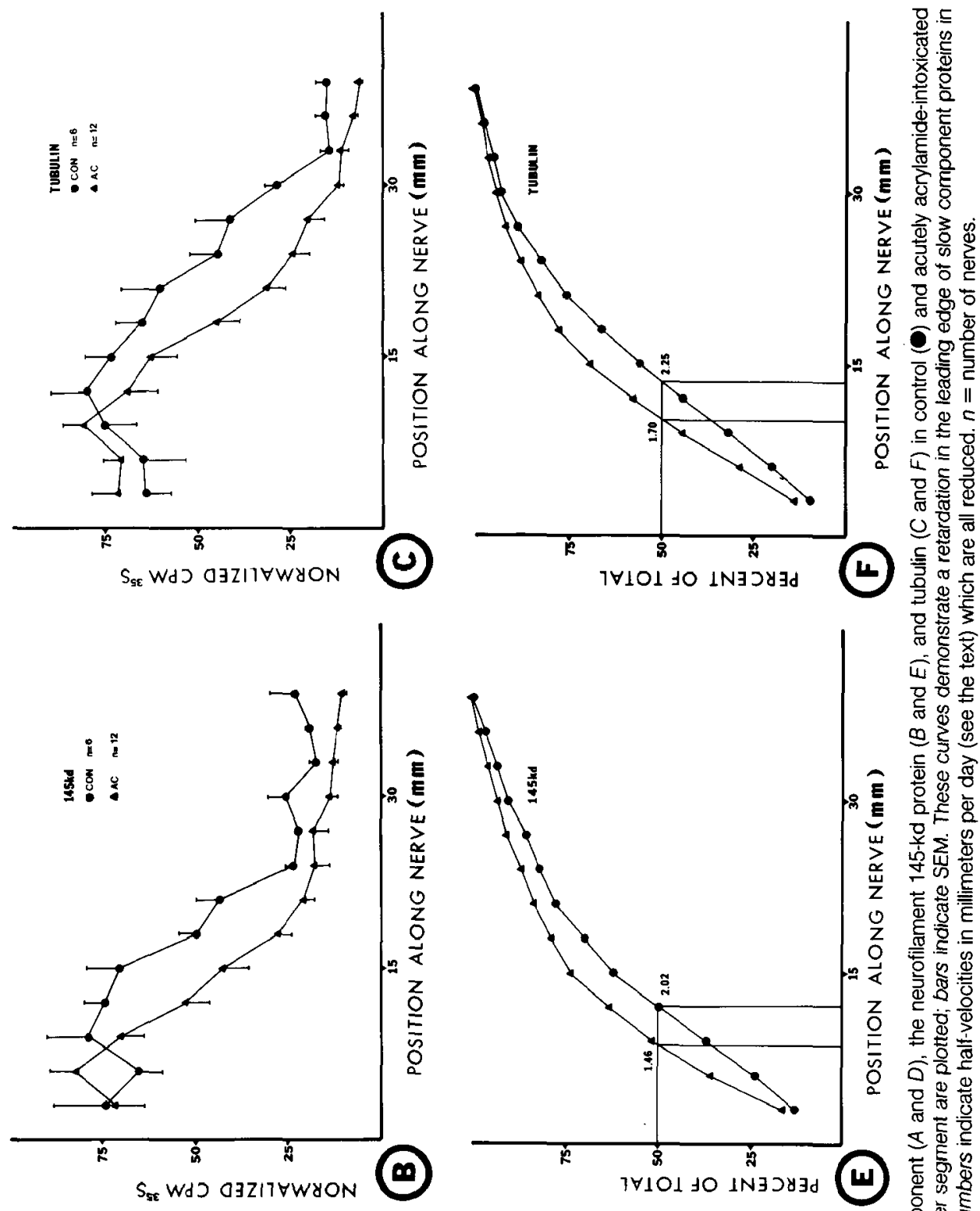

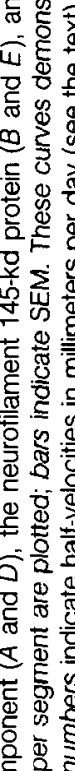

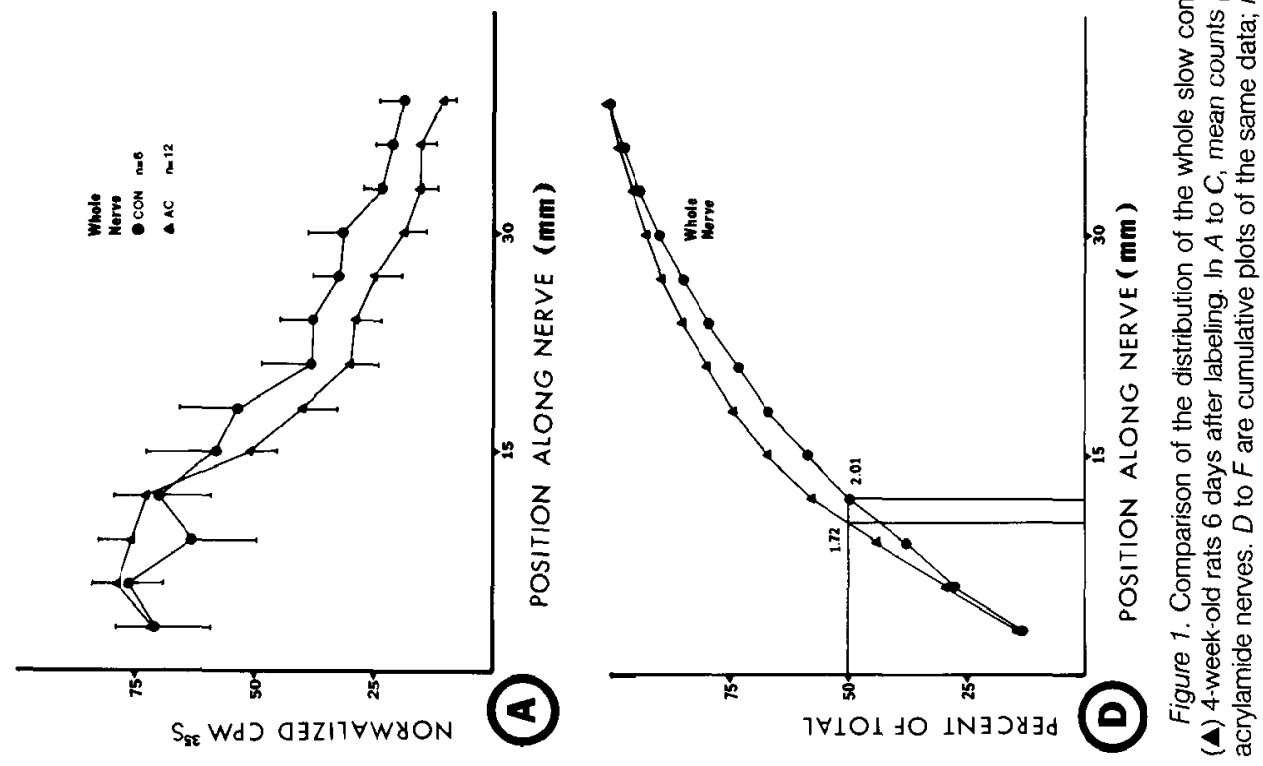



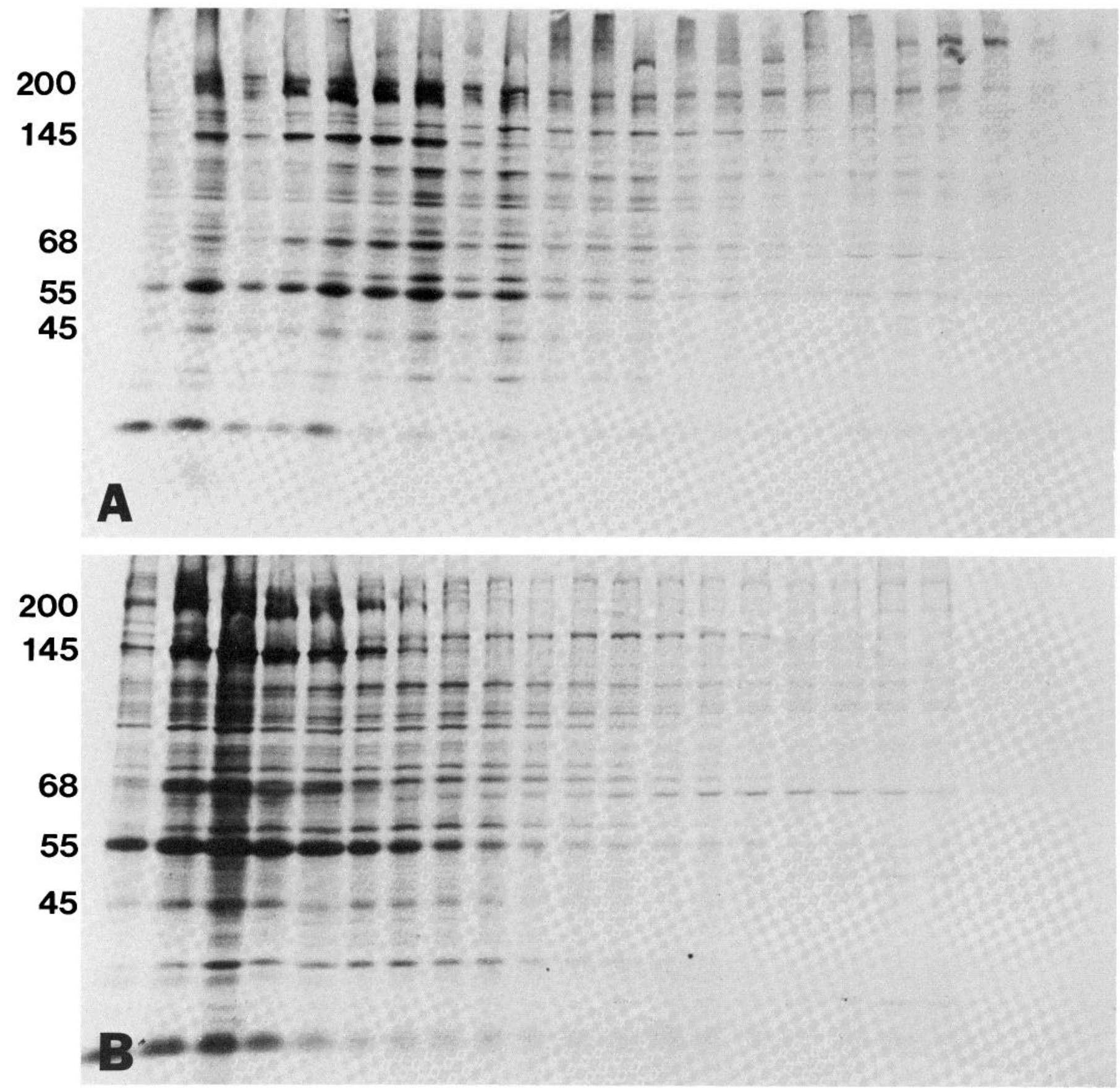

Figure 2. Fluorograms of polyacrylamide slab gels showing the slow component of axonal transport in sciatic motor nerve fibers 6 days after intraspinal injection of ${ }^{35}$ S ] methionine into 3-week-old rats. A, Normal; $B$, acute acrylamide. Each track represents a 3-mm nerve segment, extending distally to the right. Note that all slow component proteins, including the neurofilament triplet proteins ( 200,145 , and $68 \mathrm{kd})$ tubulin (55 kd), and actin (45 kd), are mildly retarded in the acrylamide-intoxicated animal.

transport along the axon should be reflected earliest in this portion of the neuron. Our results demonstrate that different intoxication protocols produce different changes in patterns of slow axonal transport and that these abnormalities correlate with types and distributions of structural pathology. Some of these findings have been reported (Gold et al., 1983).

\section{Materials and Methods}

Animals and intoxication protocols

Acute intoxication. Since the rate of slow transport is much faster in young animals (Hoffman et al., 1983), it takes less time for radiolabeled constituents to enter the peripheral nerve following isotope labeling of the spinal cord. Use of these animals allows the duration of slow transport studies to be shortened, thereby reducing concerns about the possible reversibility of changes following a single dose of the toxin. Acrylamide (Bio-Rad Laboratories, electrophoretic grade, $99 \%$ pure) was given to twelve 3-week-old Sprague-Dawley male rats as a single intraperitoneal injection $(75 \mathrm{mg} / \mathrm{kg})$ in normal saline; these animals were used for transport (eight) and morphological (four) studies. In both series of experiments, animals were sacrificed 7 days after acrylamide administration. For transport studies, isotope labeling was performed $24 \mathrm{hr}$ after injection of the toxin. These animals were sacrificed at 4 weeks of age.

Chronic intoxication. Five 3-week-old Sprague-Dawley male rats received daily intraperitoneal injections of acrylamide $(30 \mathrm{mg} / \mathrm{kg})$ in normal saline; 


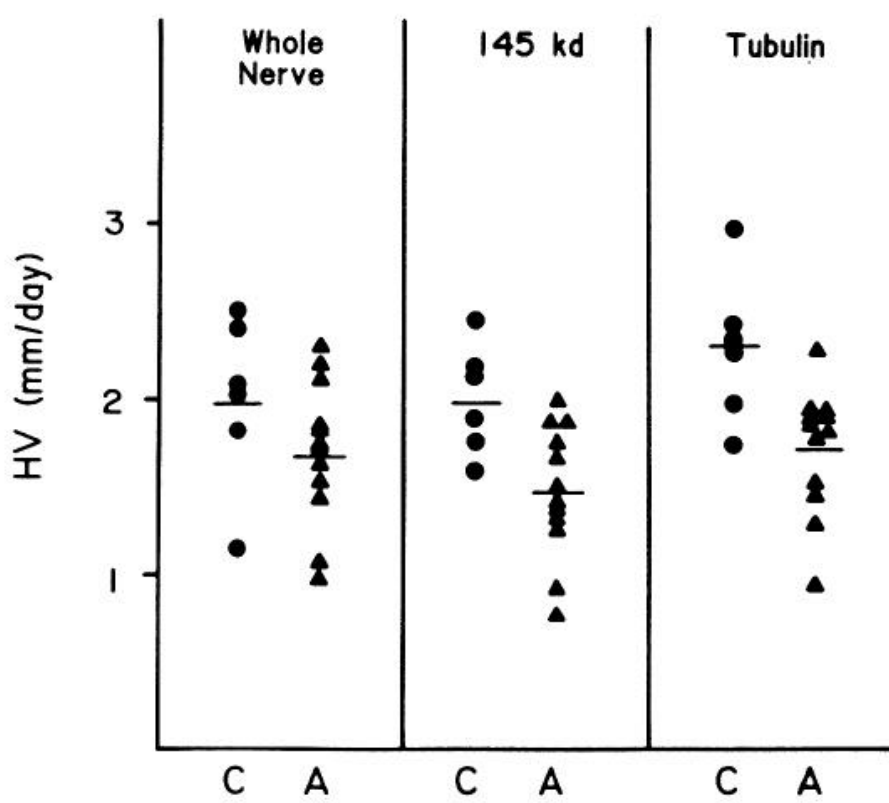

Figure 3. Plots of half-velocities (HV) for the whole slow component, the neurofilament 145 -kd protein, and tubulin from control $(C)$ and acute acrylamide $(A)$ animals. Lines indicate means. Although there is considerable overlap, all values from acrylamide-intoxicated animals display a tendency toward lower values, and mean HV are decreased (see also Table I).

TABLE I

Half-velocities (millimeters per day)

\begin{tabular}{lccc}
\hline \multicolumn{1}{c}{ Group } & Whole Nerve & 145-kd Neurofilament & Tubulin \\
\hline Control $(N=6)^{a}$ & $1.98 \pm 0.198^{\circ}$ & $1.98 \pm 0.126$ & $2.27 \pm 0.173$ \\
Acrylamide $(N=12)$ & $1.72 \pm 0.117$ & $1.50 \pm 0.108^{c}$ & $1.71 \pm 0.102^{c}$ \\
\hline
\end{tabular}

${ }^{a} N=$ number of nerves.

${ }^{b}$ Values are mean \pm SEM.

${ }^{c} p<0.05$ ( $t$ test). these animals were used for transport (two) and morphological (three) studies. For transport studies, acrylamide was administered for 17 days prior to isotope labeling, and administration was continued for an additional 7 days. For morphological studies, animals received acrylamide for 24 days. These animals were 7 weeks old at the time of sacrifice.

\section{Transport studies}

Using previously described methods (Griffin et al., 1976, 1981; Hoffman et al., 1983), the L4 and L5 ventral horns were microinjected with $\left[{ }^{35} \mathrm{~S}\right]$ methionine (specific activity, 800 to $1200 \mathrm{Ci} / \mathrm{mmol}$ ) (Amersham Corp., Arlington Heights, IL). Acutely intoxicated animals and their controls (five) were sacrificed 6 days after labeling; chronically intoxicated animals and their agematched controls (two) were sacrificed 12 days after labeling.

Each sciatic nerve was dissected from its spinal roots to its distal tibial and peroneal branches, removed, and cut into $3-\mathrm{mm}$ segments. Individual segments were homogenized in sodium dodecyl sulfate/urea/ $\beta$-mercaptoethanol (Griffin et al., 1984). Counts obtained from aliquots of the resultant solution were used to construct graphs of the distribution of slowly transported proteins along the nerve. Samples of each homogenized nerve were also applied in sequence to single tracks on a polyacrylamide slab gel (gradient 5 to $17.5 \%$ ). Following electrophoresis, the gels were fixed, stained with Coomassie blue, and dried. Radioactivity in the bands was visualized by gel fluorography.

To determine the distribution of individual slow component proteins along the nerve, specific bands were cut out of each track, dissolved, and counted as previously described (Grittin et al., 1984). The 145-kilodalton (kd) neurofilament protein was chosen for detailed analysis because, on one-dimensional gels, it is the most clearly distinguishable of the neurofilament triplet proteins. We have not directly addressed transport rate in this paper, since only one time point was studied, and we cannot rule out the possibility of a temporary stasis of outflow as opposed to a change in rate. Analysis of multiple time determinations was not possible in this study due to concerns about reversibility of changes at longer intervals (see above) and inadequate reliability of the ventral root at shorter times (see below). Comparison of the kinetics of slow transport can be performed by expressing the distribution of the radioactivity along the nerves in terms of their "half-velocity," defined as the distance in millimeters reached by half the radioactivity in a specific protein, divided by the time after labeling in days (Griffin et al., 1984). Cumulative plots were drawn of the amount of radioactivity per segment of nerve for the whole slow component and for each protein of interest (see (Fig. 1, $D$ to $F$ ). Since the radioactivity approaches background in distal nerve segments, only the first 13 segments $(39 \mathrm{~mm})$ were used to generate
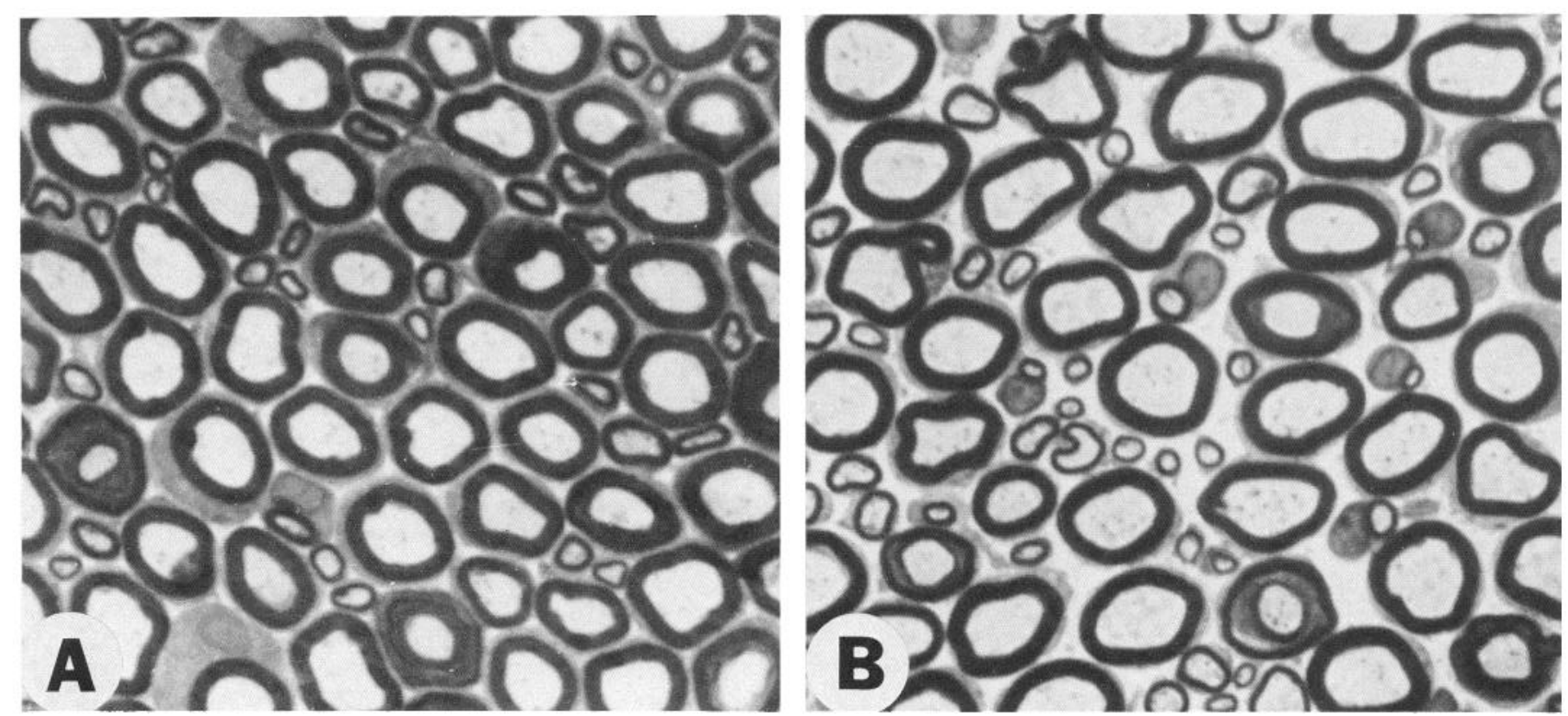

Figure 4. Light micrographs of the proximal L5 ventral roots of a control 4-week-old rat $(A)$ and a rat given a single injection of acrylamide 7 days before perfusion $(B)$. Note that fibers from the acrylamide animal are slightly larger in caliber than those from age-matched controls. Epon sections $(1 \mu \mathrm{m})$ were stained with toluidine blue. Magnification $\times 1,440$. 


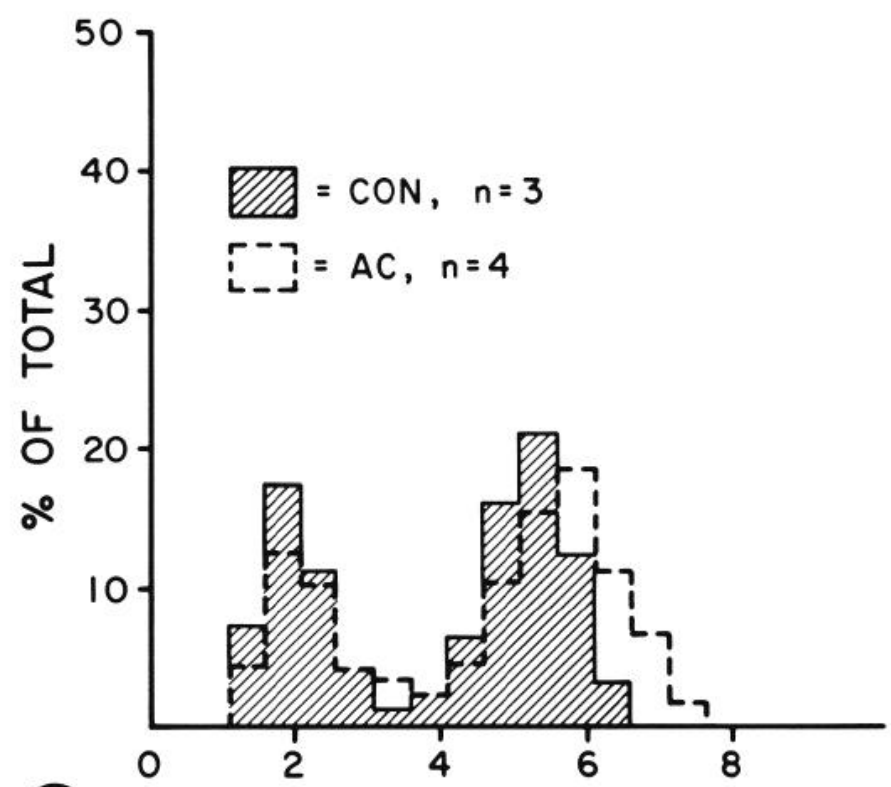

(A) AXONAL DIAMETER

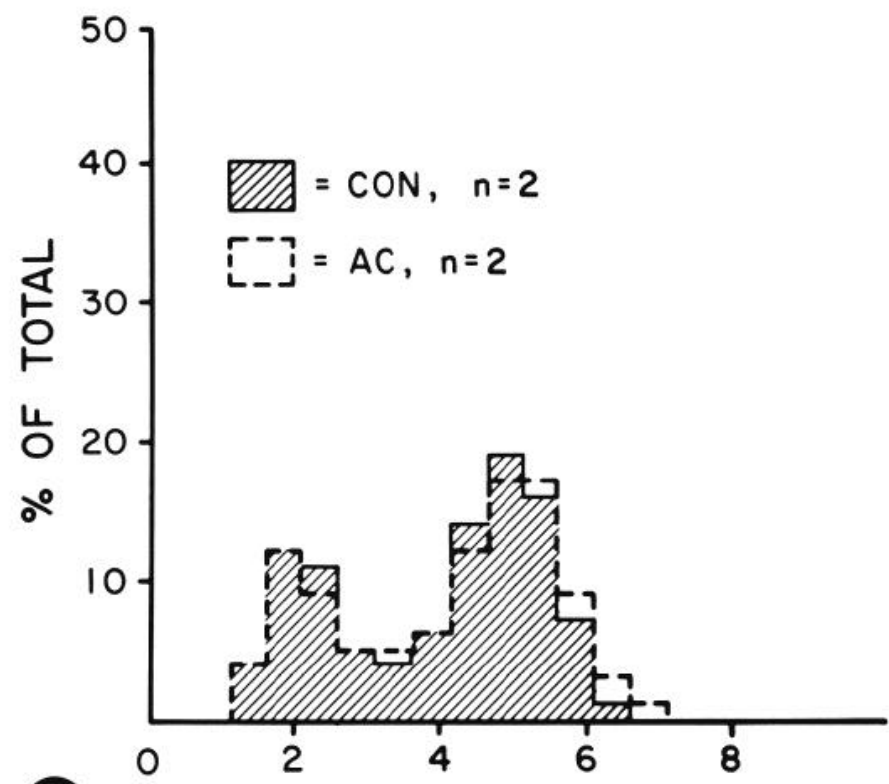

(B)

\section{AXONAL DIAMETER}

Figure 5. Comparison of axonal diameter histograms from the proximal $(A)$ and distal $(B)$ portion of the L5 ventral root of normal 4-week-old rats (solid outline, hatched histogram) and 4-week-old rats given a single injection of acrylamide 7 days before perfusion (dashed outline, open histogram). Each histogram was constructed from 761 fibers. Note that, in the proximal region, large axons from acrylamide-intoxicated animals demonstrate a modest increase in caliber. In the distal region, histograms are the same. $n=$ number of animals.

cumulative plots. Estimates of half-velocities presumably overestimate the distance of slow transport (especially for neurofilament proteins) since, at 6 days, a portion of slow component proteins is still traversing intraparenchymal segments of motor axons and has not reached ventral roots. When transport is impaired, as occurs following acrylamide intoxication, this situation will be exaggerated. Differences from control must be considered as minimal estimates. Neurofilament ( $145 \mathrm{kd}$ )-to-tubulin ratios were determined by measuring the total amount of radioactivity (dpm) for each of the two polypeptides contained within each nerve.

\section{Tissue fixation and preparation}

For morphological analysis, four acutely intoxicated animals (with three 4 week-old control rats) and three chronically intoxicated animals (with two 7 . week-old control rats) were heparinized, anesthetized with chloral hydrate, and perfused (by gravity perfusion) through the ascending aorta with $5 \%$ glutaraldehyde in $0.1 \mathrm{M}$ sodium phosphate buffer $(\mathrm{pH} 7.3)$. The following tissues were sampled: lumbar ventral horns, dorsal and ventral roots, and dorsal root ganglia at the L5 level; sciatic nerve, peroneal nerve, and posterior tibial nerve; and muscles from the hindfeet. Tissues were postfixed in osmium tetroxide, dehydrated in a graded series of alcohols, and embedded in Epon/ Araldite. Thick sections $(1 \mu \mathrm{m})$ were stained with toluidine blue; thin sections were stained with uranyl acetate and lead citrate and examined in a Hitachi $\mathrm{H}-600$ electron microscope.

\section{Morphometric studies}

Analyses of axonal caliber and fiber density were performed on preparations of the proximal (distal to the root exit zone) and distal (proximal to the dorsal root ganglia) portions of the L5 ventral root. For each animal, photographic prints (magnification $\times 2000$ ) of 200 to 300 fibers were made at each level. Axonal area was measured by tracing the inner aspect of the myelin sheath, using a Houston Instrument $\mathrm{HI}$-pad digitizer coupled to an Apple II computer; axonal diameters were calculated from area measurements. Histograms were constructed at each level of the ventral root from 761 axons in both control and experimental groups. The outer aspect of each myelin sheath was also traced to obtain areas and diameters of nerve fibers.

Neurofilament counts and density were determined on photographic prints (magnification $\times 25,000$ ) of the axoplasm of randomly selected, large myelinated fibers (three to five fibers per grid) from both levels of the ventral root; only those fibers cut in cross-section were chosen for analysis. Since neurofilaments are evenly distributed in large fibers (P. N. Hoffman and J. W. Griffin, unpublished observation), all neurofilaments from a representative field (representing approximately 60 to $75 \%$ of total axonal area) of the axoplasm of large fibers were counted, the density (neurofilaments per square micrometer) were calculated, and the total number of neurofilaments was extrapolated from the area of the axon. For small myelinated fibers, all neurofilaments within the axon were counted from photographic prints (magnification $\times 20,000$ to 30,000 ) of randomly selected fibers (three to five fibers per grid). Total number of neurofilaments was thereby determined and the density (neurofilaments per square micrometer) was calculated from the area of axons.

\section{Statistical analysis}

Ventral roots of normal and acrylamide-intoxicated animals displayed the expected bimodal distribution corresponding to large $(\alpha)$ and small $(\gamma)$ fibers (see Fig. 5). For purposes of further statistical analysis based on size, axons were separated into two groups ( $>4 \mu \mathrm{m}$ and $\leq 4 \mu \mathrm{m}$ ) and mean diameters from each group were determined. Two-way analyses of variance (ANOVAs) were performed (using an Apple $\|+$ computer), testing for the effects of position along the axon (proximal, distal) and treatment (acrylamide, control). Following these analyses, Duncan's multiple-range test was performed to test for differences between individual groups. Examination of the distribution of fibers for both acrylamide and control animals showed that the distribution displayed a slight deviation from normality. As a result, we calculated a Mann-Whitney $U$ statistic; this test makes no assumptions about the shape of the distribution. These tests confirmed the results of the Duncan multiplerange test, and these latter values are discussed in this report.

Regression analysis was performed to test the relationship between neurofilament number and axonal area for both acrylamide and control animals. In addition, two-way ANOVAs of neurofilament densities and numbers were performed for both large and small fibers to test tor the effects of position and treatment.

All values are mean \pm SEM.

\section{Results}

\section{Acute intoxication}

Clinical manifestations. All acutely intoxicated animals were clinically indistinguishable from controls at the time of transport and morphological studies.

Axonal transport. Normalized plots of the radioactivity within the 

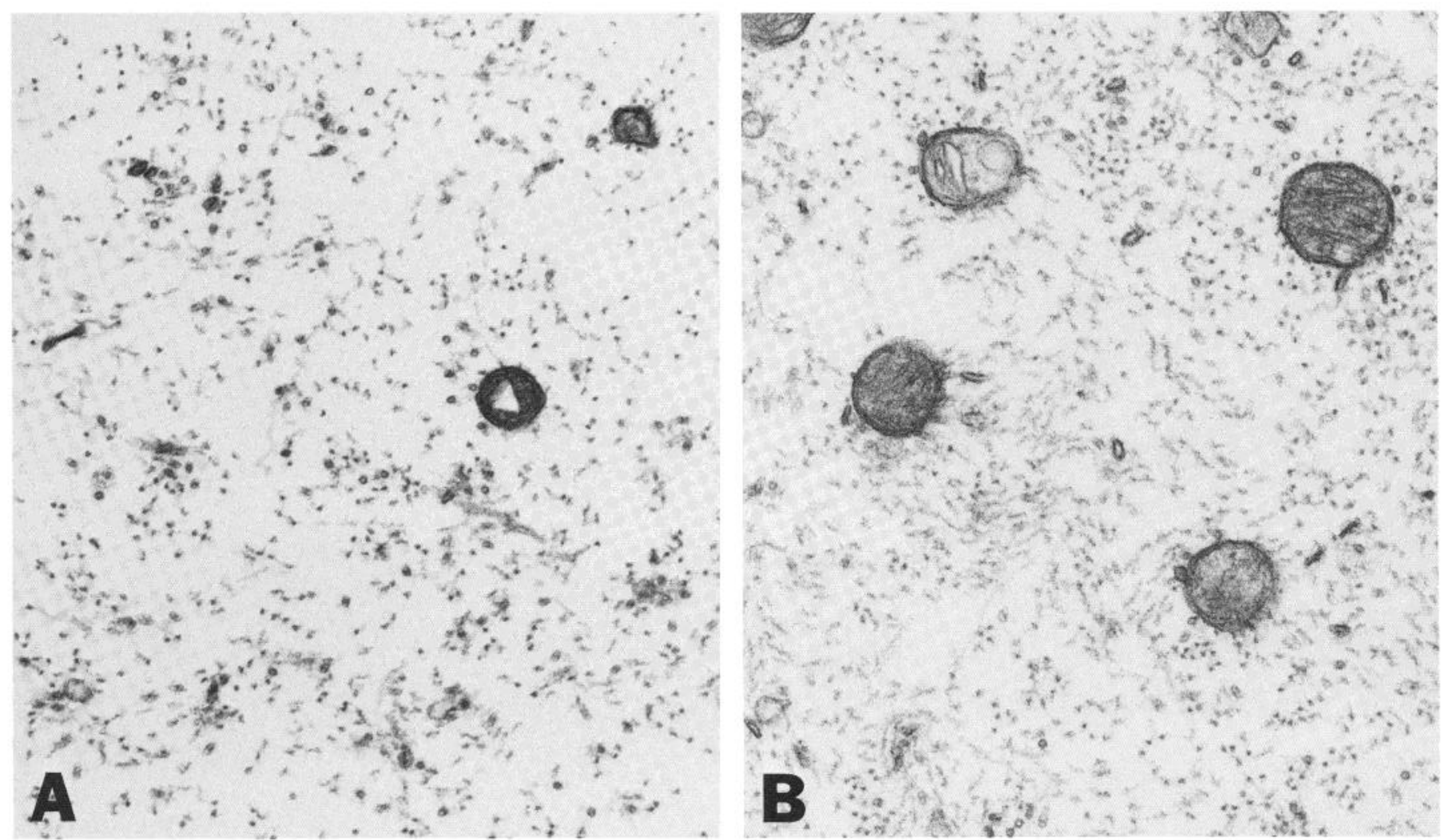

Figure 6. High power electron micrographs of typical large myelinated fibers from a control 4-week-old rat $(A)$ and a 5-week-old rat intoxicated with acrylamide $(B)$. Note that the fiber from the acrylamide animal contains more densely packed neurofilaments than does the normal fiber. Magnification $\times$ 48,240 .

whole slow component did not demonstrate striking differences between experimental and control animals in the extent of slow axonal transport (Fig. 1A). However, in acrylamide-intoxicated animals, the leading edge of radioactivity did not extend as far distally along the nerve as it did in age-matched controls. Cumulative graphs of radioactivity (Fig. 1D), calculated from these data, demonstrated a slight shift to the left in acrylamide-intoxicated animals, suggesting a modest decrease in the distance (or extent along the nerve) of slow transport.

To determine whether a selective defect existed in the transport of individual slow component polypeptides, fluorograms of gels from control and acrylamide-intoxicated animals were compared (Fig. 2, $A$ and $B$ ). As in graphs of whole nerves (Fig. 1, $A$ and $D$ ), visual inspection disclosed a modest difference in the extent of radiolabeling of individual protein bands. Normalized plots of the 145-kd neurofilament protein (Fig. 1B) and tubulin (Fig. 1C) demonstrated a modest decrease in the extent of radiolabeling along nerves of the acrylamide-intoxicated animals. When data were displayed cumulatively, a shift to the left was demonstrated for both polypeptides (Fig. 1, $E$ and $F$ ). The distribution of half-velocities (Fig. 3) for the 145-kd neurofilament protein, tubulin, and the whole slow component showed a trend toward slower rates of transport in all nerves; mean half-velocities (Table I) were reduced for these two polypeptides and for the whole slow component. Inspection of fluorograms confirmed that there was a similar decrease in distances of transport for all slow component polypeptides.

Morphometric studies. Structural correlates of this change in slow transport were assessed in morphometric studies. Light microscopy of proximal portions of L5 ventral roots suggested a slightly larger caliber of fibers from acutely intoxicated animals as compared with age-matched controls (Fig. 4). Histograms of axonal diameters determined from these fibers (Fig. 5A) demonstrated a consistent, mild shift toward greater diameters in large myelinated axons from acrylamide-intoxicated animals. Mean diameters for large myelinated axons were significantly increased $(p<0.05)$. Control values were $5.16 \mu \mathrm{m}$, and experimental values were $5.65 \mu \mathrm{m}-\mathrm{a} 20 \%$ increase in mean axonal area in acrylamide-intoxicated animals. Whereas the largest axons obtained from control animals did not exceed $6.7 \mu \mathrm{m}$ in diameter, $7 \%$ of axons from acrylamide-intoxicated animals achieved a diameter greater than that of the largest control, reaching diameters up to $7.4 \mu \mathrm{m}$. Although mean diameters for small myelinated axons were also significantly increased $(p<0.05$; data not shown), this was not apparent upon inspection of histograms (Fig. $5 A$ ), and neurofilament content was unaltered (see below). Moderately large axonal swellings containing densely packed neurofilaments were also observed in some dorsal root fibers near cell bodies of dorsal root ganglia (data not shown).

To determine whether these changes in diameter occurred locally or extended all along the length of the nerve, we repeated the morphometric analysis in distal regions of the L5 ventral root. In this region, the distribution of fiber sizes was identical between control and acrylamide nerves (Fig. 5B). Mean axonal diameters and fiber diameters (data not shown) for both small and large myelinated axons were not significantly different between acrylamide-intoxicated animals and controls.

Ultrastructural studies. Large myelinated fibers in L5 ventral roots of acrylamide-intoxicated animals appeared to have more densely packed neurofilaments within their axoplasm than did fibers from age-matched controls (Fig. 6). Neurofilaments and microtubules often appeared maloriented in fibers from acrylamide-intoxicated animals. In control animals, neurofilament density was the same in fibers of all sizes (Table II, Fig. 7A); regression analysis demonstrated 
PROXIMAL VENTRAL ROOT
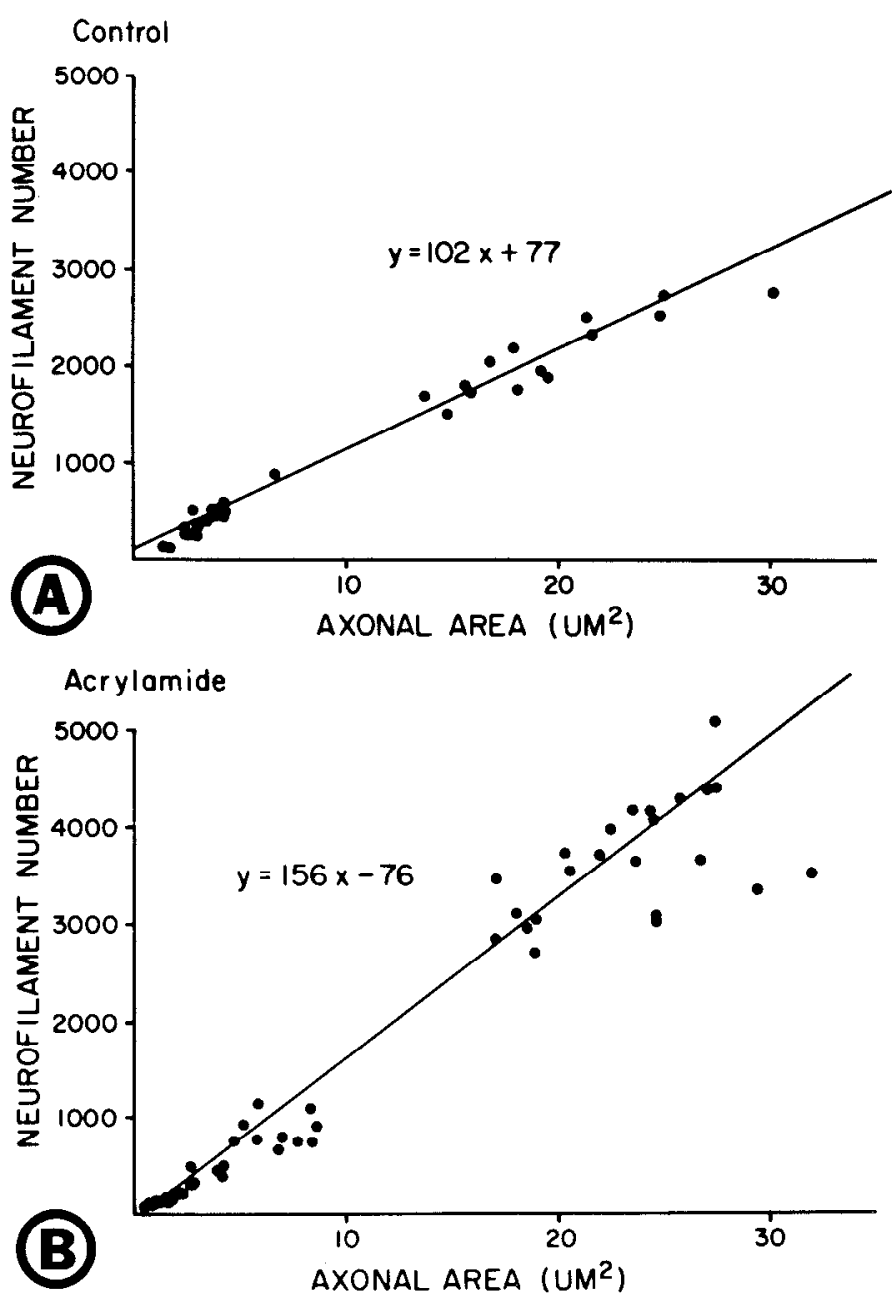

DISTAL VENTRAL ROOT
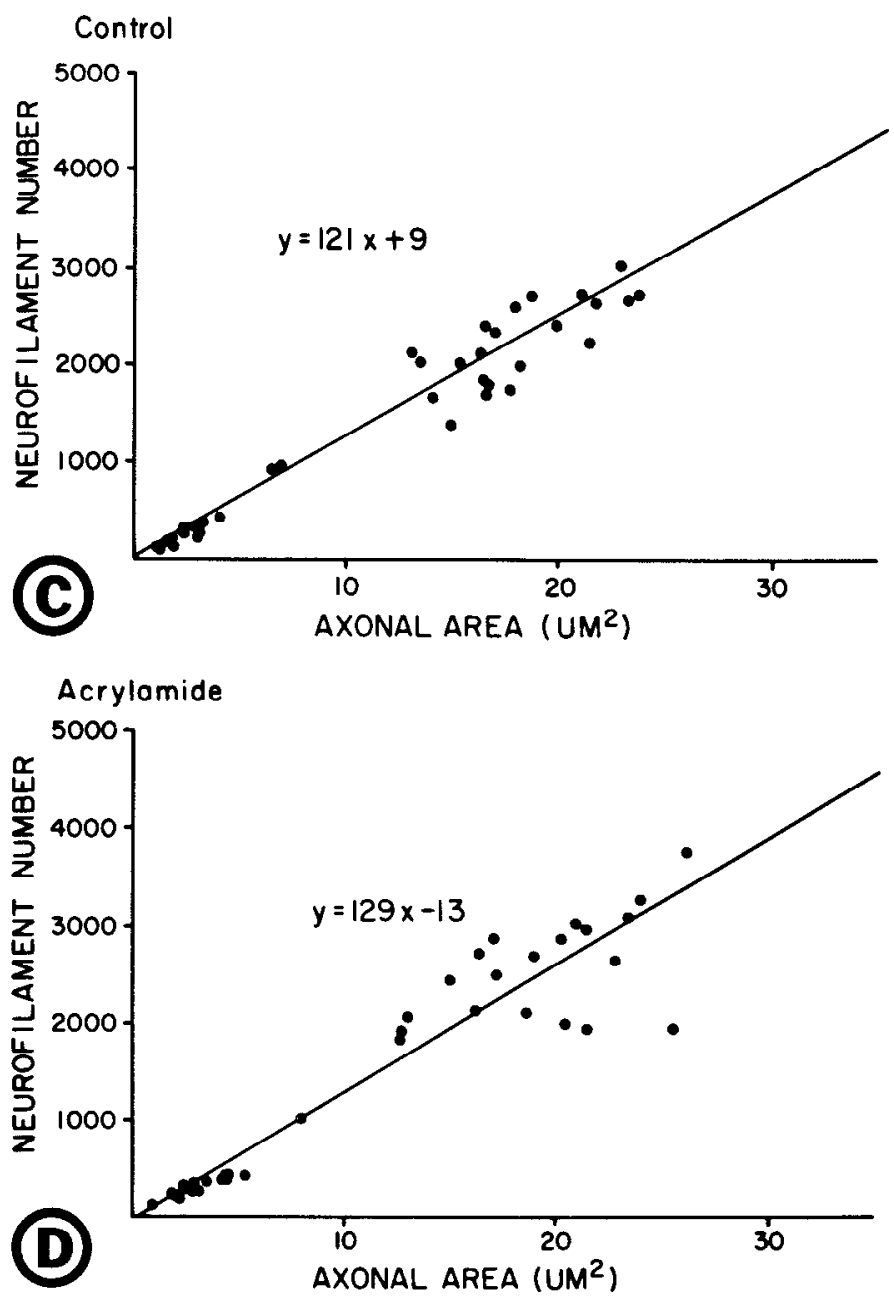

Figure 7. Plots of neurofilament number versus axonal area from proximal $(A$ and $B)$ and distal $(C$ and $D)$ portions of the $L 5$ ventral root in normal 4 -weekold rats $(A$ and $C)$ and in 4-week-old rats acutely intoxicated with acrylamide $(B$ and $D)$. Both large and small fibers are shown on the same graphs. In control fibers $(A$ and $C$ ), there is a linear relationship of neurofilament number and axonal area; neurofilament density (slope of the line) is the same in fibers of all sizes. In fibers from acrylamide-intoxicated animals, the slope is increased in the proximal portion of the fibers $(B)$. The slope is not altered in the distal portion of the nerve $(D)$, although there is a poor correlation of the regression line (see the text).

TABLE ॥

Neurofilaments (NFs) - proximal ventral root

\begin{tabular}{llllll}
\hline \multirow{2}{*}{ Group } & \multicolumn{2}{c}{ Large Fibers } & & \multicolumn{2}{c}{ Small Fibers } \\
\cline { 2 - 3 } \cline { 5 - 6 } & $\begin{array}{c}\text { Density } \\
\left(\mathrm{NFs} / \mu \mathrm{m}^{2}\right)\end{array}$ & Total No. of NFs & $\begin{array}{c}\text { Density } \\
\left(\mathrm{NFs} / \mu \mathrm{m}^{2}\right)\end{array}$ & Total No. of NFs \\
\hline Control & $108 \pm 2.7^{a}$ & $2090 \pm 110.0$ & & $117 \pm 6.0$ & $403 \pm 42.1$ \\
$(N=3)^{b}$ & $(n=14)^{c}$ & $(n=14)$ & & $(n=18)$ & $(n=18)$ \\
Acrylamide & $158 \pm 4.9^{d}$ & $3615 \pm 125.2^{d}$ & & $117 \pm 5.8$ & $404 \pm 54.5$ \\
$(N=4)$ & $(n=23)$ & $(n=23)$ & $(n=34)$ & $(n=34)$ \\
\hline
\end{tabular}

${ }^{a}$ Values are mean \pm SEM.

${ }^{b} \mathrm{~N}=$ number of animals.

${ }^{c} n=$ number of fibers.

${ }^{d} p<0.05$

a significant correlation $(r=0.99 ; p<0.05)$ in neurofilament density (i.e., slope of the line) between large and small fibers (Fig. $7 A$ ). In proximal roots of acrylamide-intoxicated animals, mean neurofilament density and total number of neurofilaments (Table II. Fig. 7B) were significantly increased in large myelinated fibers; the total number of neurofilaments in the largest fibers was markedly in-
TABLE III Neurofilaments (NFS) - distal ventral root

\begin{tabular}{llllll}
\hline \multirow{2}{*}{ Group } & \multicolumn{2}{c}{ Large Fibers } & & \multicolumn{2}{c}{ Small Fibers } \\
\cline { 2 - 3 } \cline { 5 - 6 } & $\begin{array}{c}\text { Density } \\
\left(\mathrm{NFs} / \mu \mathrm{m}^{2}\right)\end{array}$ & Total No. of NFs & $\begin{array}{c}\text { Density } \\
\left(\mathrm{NFs} / \mu \mathrm{m}^{2}\right)\end{array}$ & Total No. of NFs \\
\hline Control & $123 \pm 3.9^{2}$ & $2206 \pm 92.3$ & & $114 \pm 6.1$ & $371 \pm 73.2$ \\
$(\mathrm{~N}=2)^{b}$ & $(n=22)^{\circ}$ & $(n=22)$ & & $(n=16)$ & $(n=16)$ \\
Acrylamide & $134 \pm 5.5$ & $2522 \pm 119.5$ & $106 \pm 4.7$ & $348 \pm 46.6$ \\
$(\mathrm{~N}=2)$ & $(n=20)$ & $(n=20)$ & $(n=17)$ & $(n=17)$ \\
\hline
\end{tabular}

${ }^{a}$ Values are mean \pm SEM.

${ }^{\circ} \mathrm{N}=$ number of animals.

${ }^{c} n=$ number of fibers.

creased (Fig. 7B). Although there was an abnormally large scatter in the distribution of data $(r=0.54)$, the majority $(75$ to $80 \%$ ) of large fibers demonstrated this increase in neurofilament number. Small fibers demonstrated no significant alteration in neurofilament density or total number of neurofilaments (Table II); increase in the slope of the regression line (i.e., neurofilament density) in fibers of 


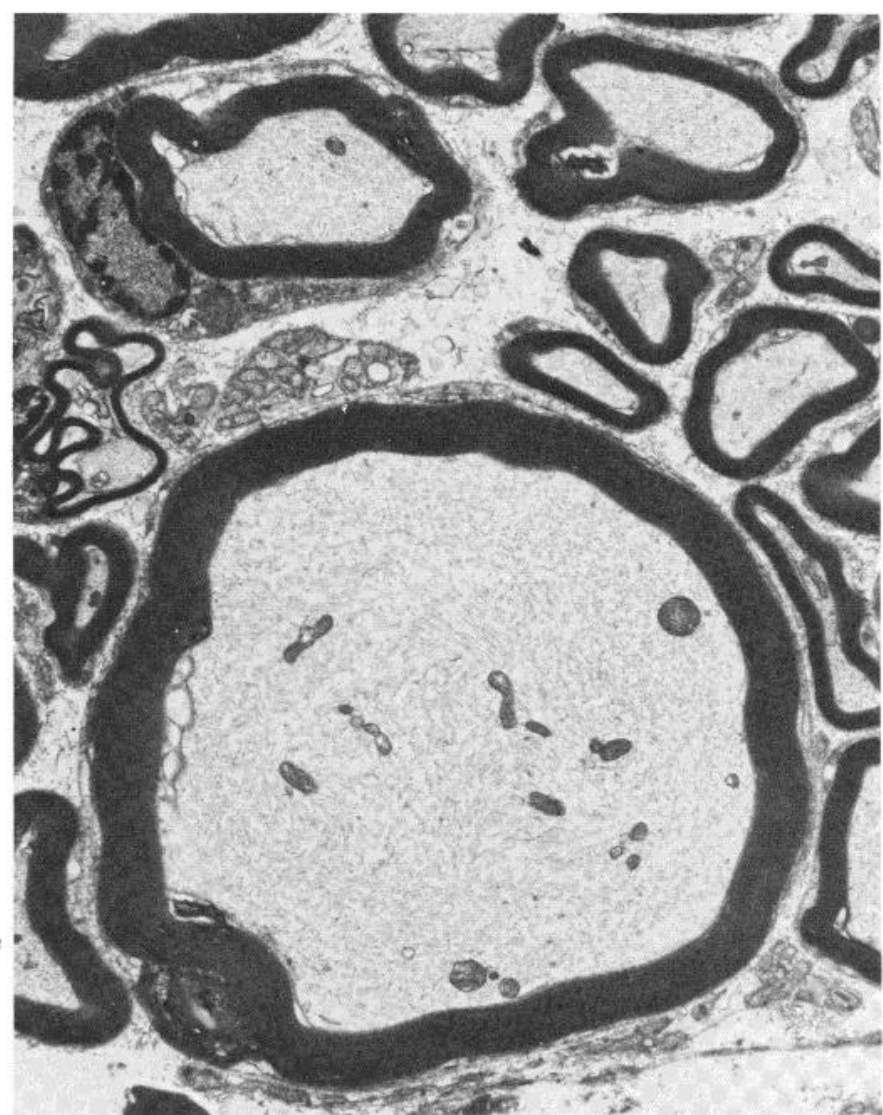

Figure 8. Electron micrograph of a proximal giant axonal swelling from a dorsal root fiber within the dorsal root ganglia. A 3-week-old rat was given a single injection of acrylamide ( $75 \mathrm{mg} / \mathrm{kg}$, i.p.) followed by daily injections (30 $\mathrm{mg} / \mathrm{kg}$, i.p.) for a total of 10 days. Note the large size of the axon, the relative thinness of the myelin sheath, and the numerous neurofilaments within the axoplasm. Such giant swellings were only occasionally observed. Magnification $\times 4,370$.

all sizes from acrylamide-intoxicated animals reflects the increase in neurofilament density in large fibers (Fig. 7B).

In distal ventral roots of control animals, the mean neurofilament density was the same in fibers of all sizes $(r=0.97 ; p<0.05)$, and there were no significant differences in neurofilament density or total number of neurofilaments between proximal (Table II) and distal (Table III) portions of ventral roots. When control and acrylamideintoxicated animals were compared, there were no significant differences in mean neurofilament density or total number of neurofilaments in either large or small myelinated fibers from the distal portion of the L5 ventral root (Table III, Fig. 7, C and D). The relationship between neurofilament number and axonal diameter for the large fibers in acrylamide-intoxicated animals showed a nonsignificant correlation $(r=0.55)$. Examination of data on acrylamide-intoxicated animals (Fig. 7D) revealed that, at a given fiber size, axons may show an abnormal increase or decrease in the total number of neurofilaments, suggesting at least two different relationships.

Typical giant neurofilamentous axonal swellings were produced in rats given a single high dose $(75 \mathrm{mg} / \mathrm{kg}$, i.p.) of acrylamide followed by daily injections at a lower level of intoxication ( $30 \mathrm{mg} / \mathrm{kg}$, i.p.) for a total of 10 days. These changes were observed in dorsal root fibers near cell bodies of dorsal root ganglia (Fig. 8).

At this time, axonal degeneration was not observed in distal nerves, in intramuscular nerve branches, or at neuromuscular junctions.

\section{Chronic intoxication}

Clinical manifestations. All chronically intoxicated acrylamide animals showed mild clinical signs by 17 days after the first injection of the toxin, i.e., at the time of isotope labeling. Animals demonstrated mild ataxia, wide gait, and low stance in the hindlimbs. Between the third and fourth week of intoxication, animals became extremely weak. Acrylamide administration was discontinued during the last 5 days of study, during which time the animals' conditions continued to worsen.

\section{Axonal transport}

Chronically intoxicated animals displayed striking alterations in the pattern of slow axonal transport. Typical examples of gel fluorographs from control and acrylamide-intoxicated animals are illustrated in Figure 9, $A$ and $B$, respectively; the distribution of radiolabeling in these two nerves for tubulin, actin, and the 145-kd neurofilament protein are shown in Figure 10, $A$ and $B$, respectively. Examination of gel fluorograms (Fig. $9 A$ ) and plots of radioactivity from control animals (Fig. $10 A$ ) revealed a normal pattern 12 days after labeling; the faster-moving fraction of tubulin and actin (SCb) separated from the slower moving ( $\mathrm{SCa}$ ) polypeptides which include the 145-kd neurofilament protein. Acrylamide-intoxicated animals (Figs. $9 B$ and $10 B$ ) displayed two important differences from controls. First, the distribution of tubulin and actin shifted relative to controls in that the more distal portion of the nerve from experimental animals showed a heavier amount of labeling at this time (i.e., there was an increase in the transport velocity for these polypeptides). $\mathrm{SCb}$ marker proteins also demonstrated a greater extent of radiolabeling in the distal part of the nerve (cf. Fig. 9, $A$ and B). Second, when compared to controls, the 145-kd neurofilament protein in acrylamide-intoxicated animals showed much less relative radiolabeling than did tubulin and actin (cf. Figs. 9, $A$ and $B$, and 10, $A$ and $B$ ). Neurofilaments (145-kd neurofilament protein-to-tubulin ratios) were significantly reduced $(p<0.05 ; t$ test) from $0.34 \pm 0.036$ in the control animals to $0.19 \pm 0.038$ in acrylamide-intoxicated animals, representing a $44 \%$ decrease in relative neurofilament labeling. However, there was no apparent alteration in the distance of transport (as seen from the distribution of radioactivity (Fig. 10)) of the $145-\mathrm{kd}$ neurofilament protein.

Morphology. At the time of the transport study, pathological changes were most prominent at the level of the dorsal root ganglia (Fig. 11). Dorsal root fibers demonstrated a marked decrease in caliber which was most apparent near their cell bodies (Fig. 11B); axonal atrophy was recognized by the relative small size of axons and the crenated appearance of the myelin sheath. At a slightly more rostral level of the L5 dorsal root $(\sim 1 \mathrm{~mm})$ (Fig. 12), axonal atrophy was still appreciable within the dorsal root. In more rostral regions, caliber appeared normal.

At this time, axonal degeneration was present in distal portions of nerves of chronically intoxicated animals. Electron microscopy revealed a mixture of both normal-appearing (Fig. 13A) and denervated (Fig. 13B) neuromuscular junction and muscule spindles (Fig. $13 C$ ) of the hindfeet. Axonal swellings, characteristic of chronic acrylamide intoxication, were observed within intramuscular nerve branches (Fig. 13D)

\section{Discussion}

Direct toxic effects of acrylamide. Acute acrylamide intoxication causes a mild increase in axonal diameter in the proximal portion of large myelinated fibers. These proximal axonal enlargements contain an increased density of neurofilaments. A few fibers form typical giant axonal swellings. Taken together, the increased size and increased neurofilament density reflect a substantial increase $(70 \%)$ in neurofilament content within the proximal portion of large myelinated fibers. At this time, alterations in caliber and neurofilament density do not extend into more distal regions of the nerve. We 

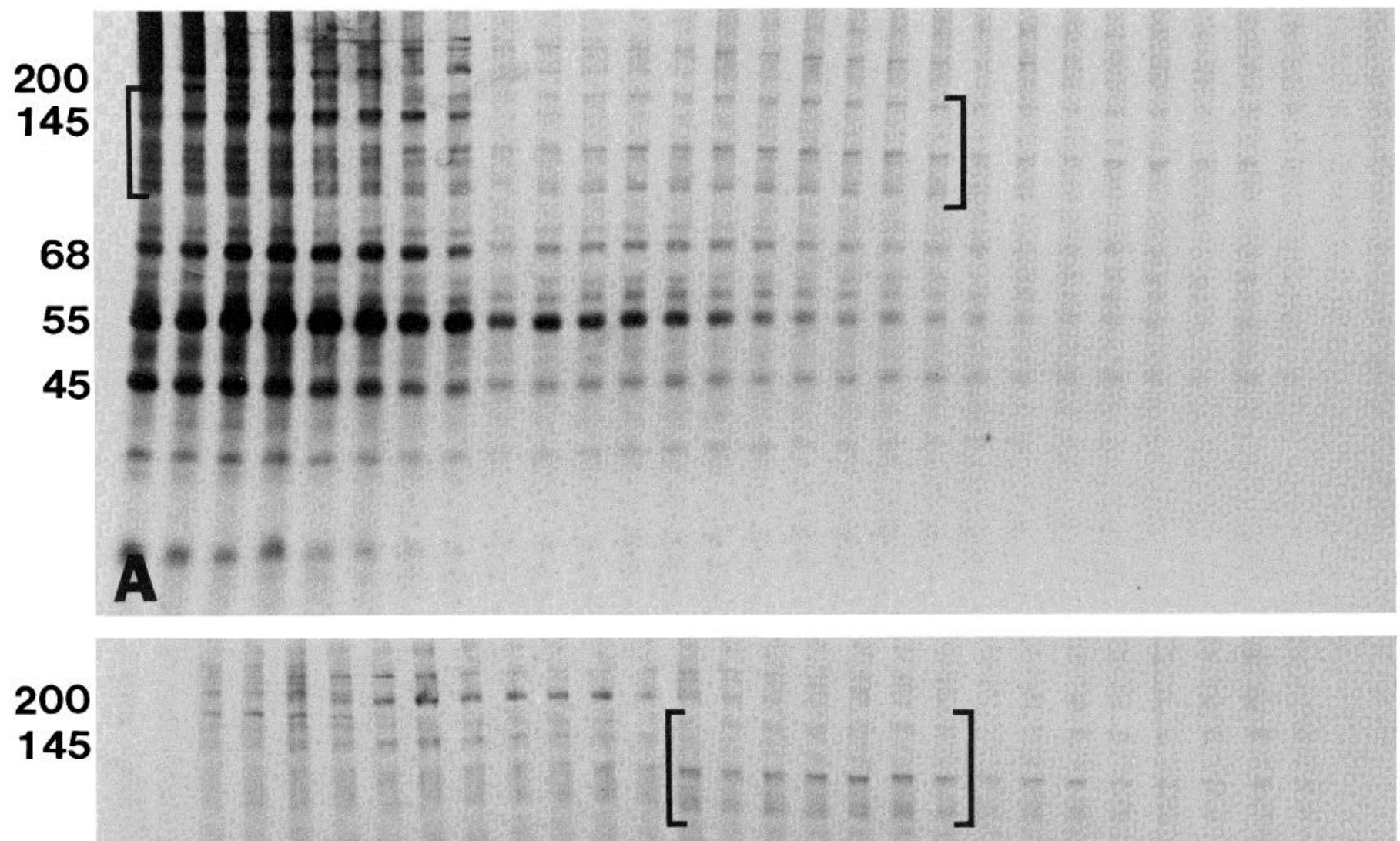

68

55

45
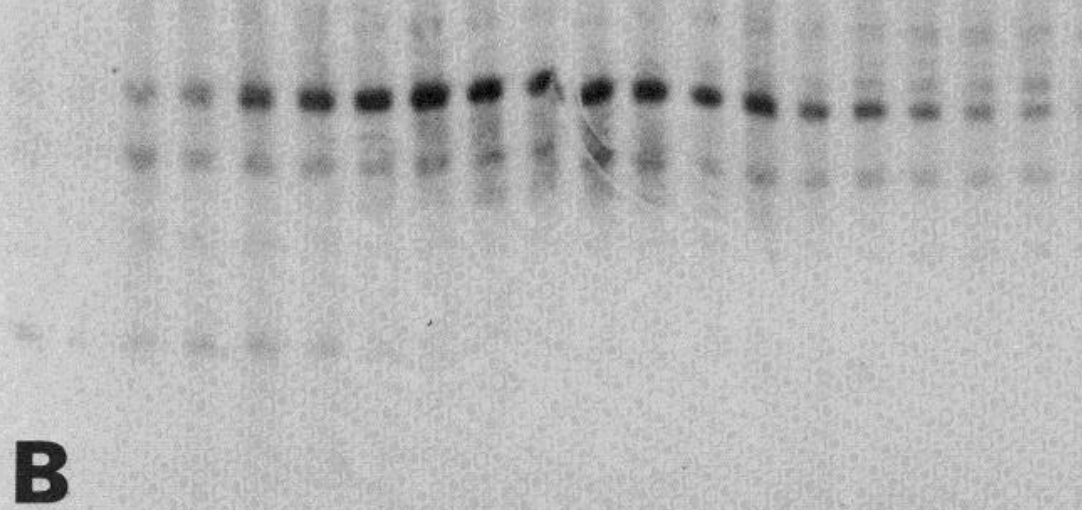

Figure 9. Fluorograms of polyacrylamide slab gels showing the slow component of axonal transport in sciatic motor nerve fibers 12 days after intraspinal injection of ${ }^{35}$ S ]methionine into 5 -week-old rats. $A$, Normal; $B$, chronic acrylamide. Note that the fluorogram from the chronically intoxicated acrylamide animal demonstrates a decrease in the relative abundance of the neurofilament triplet proteins $(200,145$, and $68 \mathrm{kd})$ and an increase in the rate of transport for tubulin $(55 \mathrm{kd})$, actin $(45 \mathrm{kd})$, and SCb proteins (heaviest labeling demarcated by brackets). The appearance of the flurogram from the chronically intoxicated animal is similar to that observed following axotomy (Hoffman and Lasek, 1980).

suggest that the proximal neurofilamentous change is the structural correlate of the slow transport defect, reflecting continued delivery of neurofilaments from the cell body but retarded movement down the axon.

This retardation, a 20 to $25 \%$ decrease in the distance of slow transport, involved all slow component proteins equally. This alteration differs both quantitatively and qualitatively from changes described in previous studies of toxic neurofibrillary disorders. In contrast to the general effects of acrylamide on transport of individual slow component proteins, other agents appear to be more selective. Colchicine preferentially impairs transport of tubulin (Komiya and Kurokawa, 1980), whereas $\beta, \beta^{\prime}$-iminodipropionitrile and 3,4-dimethyl-2,5-hexanedione (DMHD) - agents which produce prominent large neurofilamentous swellings in proximal axons - retard transport of neurofilament triplet proteins selectively and severely (75 to $90 \%$ ) (Griffin et al., 1984). The alteration in transport following acrylamide intoxication is quite modest in comparison with the alteration after these agents, and it is unlikely that such a modest alteration in the rate of slow transport could, in itself, lead to distal axonal degeneration following prolonged acrylamide intoxication. However, there is evidence to suggest that fast axonal transport may be compromised following chronic (Sahenk and Mendell, 1981; Jakobsen and Sidenius, 1983) or acute (Miller et al., 1983) acrylamide exposure. Thus, the distal axonal degeneration occurring in acrylamide intoxication may result from an effect upon multiple components of axonal transport. An alteration in energy metabolism has been suggested 
Figure 10. Comparison of the distribution of radioactive tubulin, actin, and the $145-\mathrm{kd}$ neurofilament protein in control $(A)$ and chronically acrylamide-intoxicated $(B) 7$. week-old rats (same data as in Fig. 9). These curves show an increase in the transport rates for tubulin and actin and a relative decrease in the radiolabeling of the $145-\mathrm{kd}$ neurofilament protein.

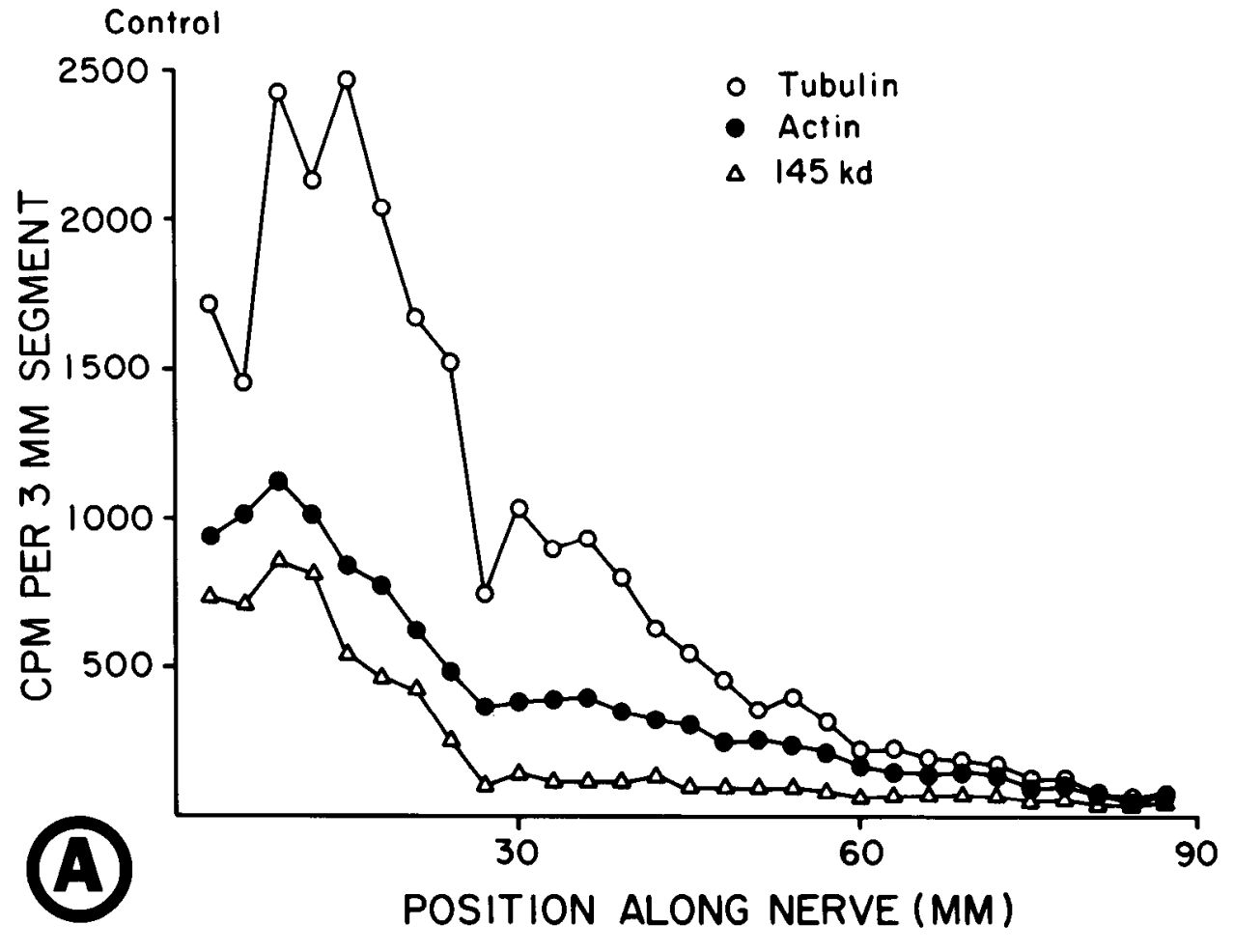

Acrylamide

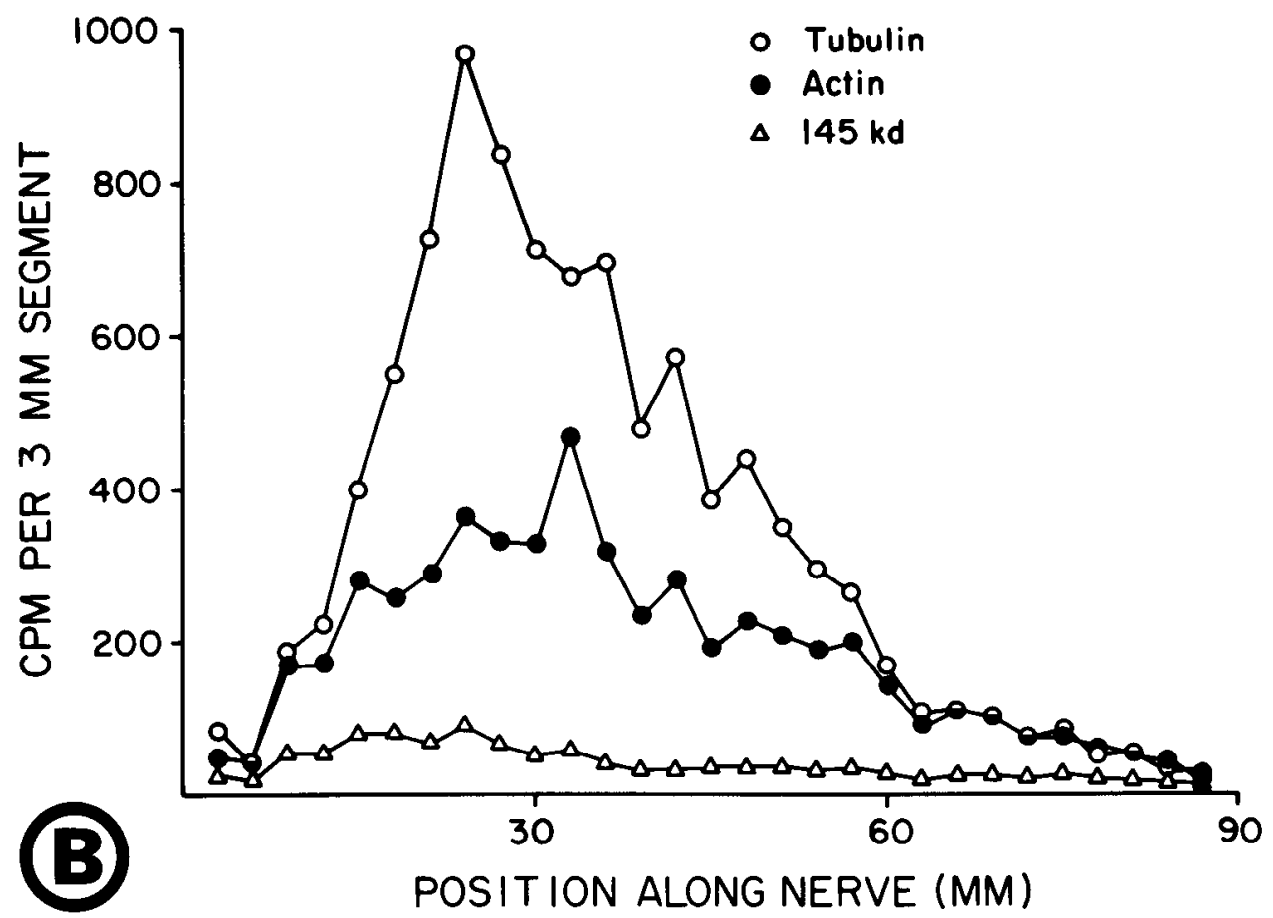

as one mechanism of toxicity (Spencer and Schaumburg, 1977; Spencer et al., 1979; Cavanagh, 1982), and there is some experimental evidence supporting an inhibition of some glycolytic (Howland et al., 1980; Howland, 1981) and oxidative (Sickles and Goldstein, 1985) enzymes. Thus, acrylamide could produce its neurotoxicity by a direct toxic effect upon mechanisms of transport or by causing a defect in energy metabolism and a general compromise of many energy-dependent cellular functions, including axonal transport.
In the present model, neurofilamentous axonal swellings arose within the proximal portion of large myelinated fibers following a single high dose of acrylamide. This differs from chronic models in which acrylamide produces distal neurofilamentous axonal swellings (Prineas, 1969; Suzuki and Pfaff, 1973; Schaumburg et al., 1974; Spencer and Schaumburg, 1974, 1977). Studies on DMHD (Anthony et al., 1983a, b) suggest that the distribution (proximal versus distal) of neurofilamentous axonal enlargements depends upon the relative potency of the toxic agent and the schedule of administration. 

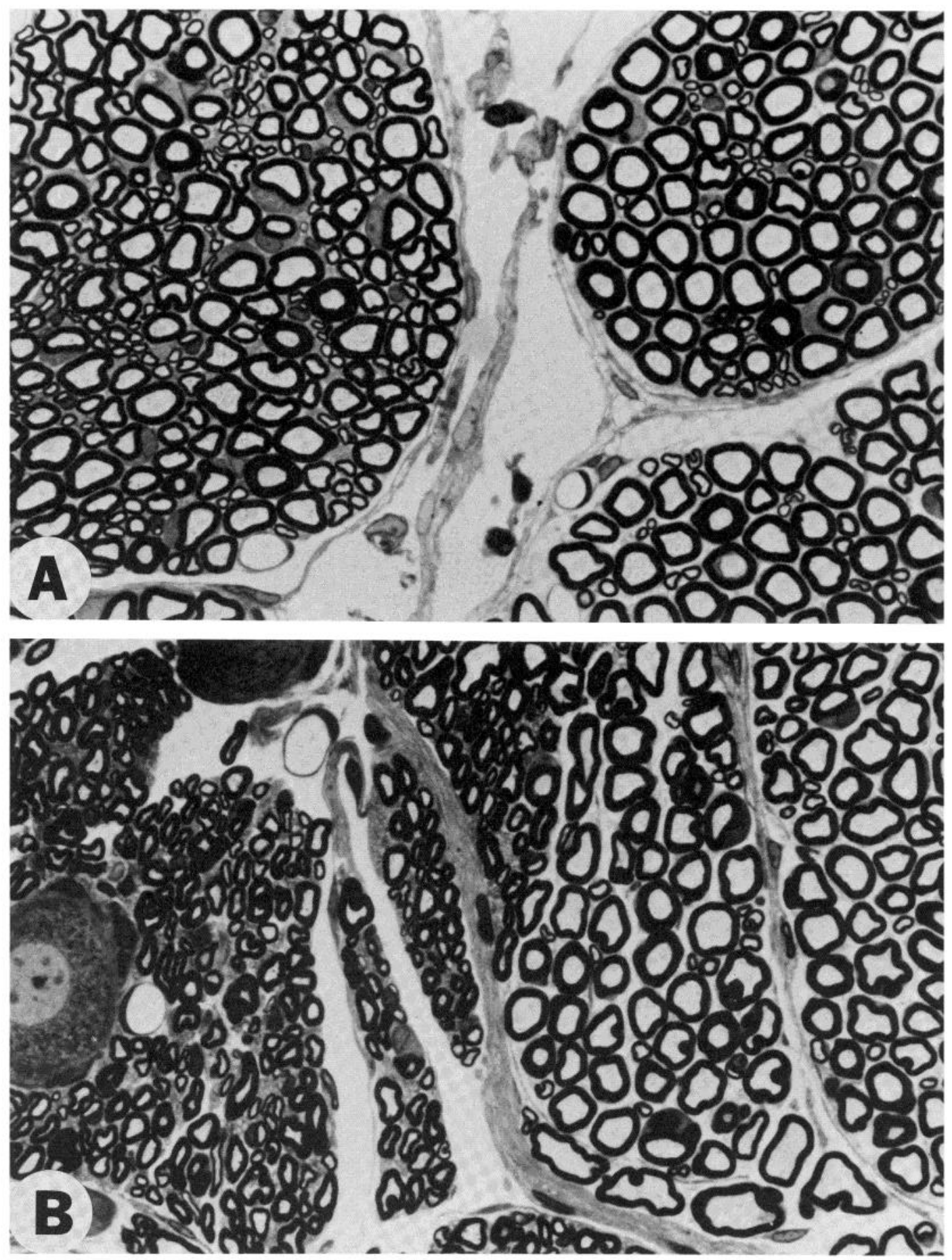

Figure 11. Light micrographs of dorsal (left) and ventral (right) root fibers at the level of the L5 dorsal root ganglia of control $(A)$ and chronically acrylamideintoxicated $(B)$ 7-week-old rats. Note that the dorsal root fibers from the acrylamide animal are markedly atrophic at this very proximal level; dorsal root ganglia cell bodies are present among the fibers of the nerve. Ventral root fibers appear normal. Epon sections (1 $\mu \mathrm{m})$ were stained with toluidine blue. Magnification $\times 700$.

Acrylamide may be relatively weak in terms of its ability to impair neurofilament transport and produce axonal swellings, but a sufficient dose can produce proximal swellings.

Cytoskeletal changes associated with the generalized retardation of the slow component were restricted to neurofilaments. Tubulin was severely retarded in its rate of transport, but an increase in microtubules was not observed. Actin was also retarded, as shown by gel fluorography, but there was no accumulation of microfilaments. Thus, despite an increased abundance of these two proteins within the proximal portion of the ventral root, electron microscopy did not reveal an increase in the polymerized forms of these cytoskeletal proteins (i.e., microtubules and microfilaments). This may be due to the capacity of microtubules and actin filaments to disaggregrate and be transported as soluble subunits within the 

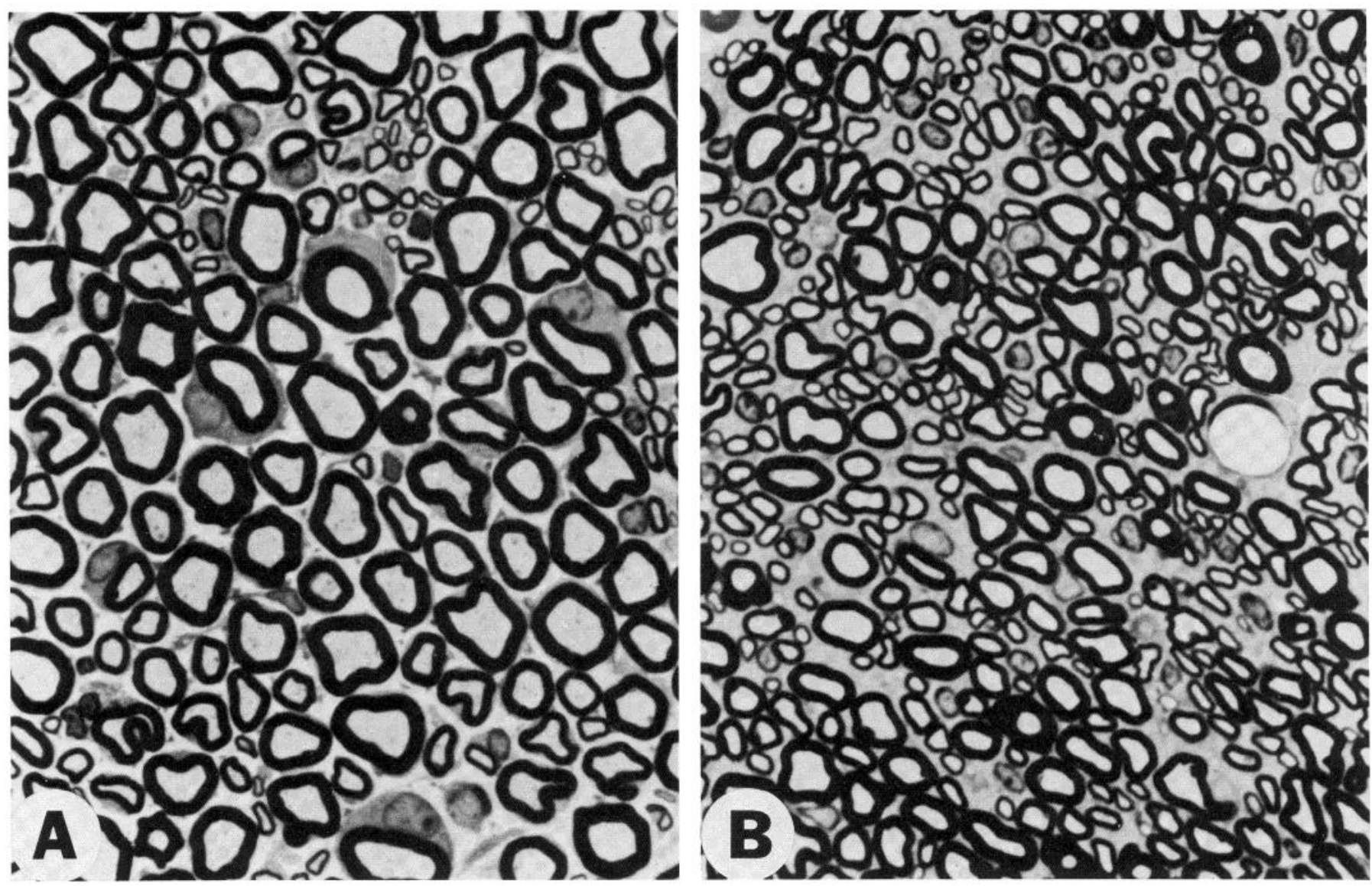

Figure 12. Light micrographs of dorsal root fibers of the $L 5$ dorsal root ganglia of control $(A)$ and chronically acrylamide-intoxicated $(B) 7$-week-old rats. These sections are taken from the same animals at a slightly more rostral level of the L5 dorsal root than those in Figure 11. Note that these fibers are still atrophic, although the degree of atrophy is less than that observed closer to the cell bodies. Epon sections $(1 \mu \mathrm{m})$ were stained with toluidine blue; $\times 1,150$

axon (Morris and Lasek, 1984). In contrast, neurofilament triplet proteins appear to exist in the axon only as the assembled organelle (Lasek and Hoffman, 1976; Morris and Lasek, 1982), undergoing degradation at nerve terminals by calcium-activated proteases (Lasek and Hoffman, 1976; Roots, 1983). Thus, the ability to regulate the polymerization of tubulin and actin along the length of the axon may account for the lack of structural correlates for the decreased rate of transport of these polypeptides.

Secondary alterations following chronic acrylamide intoxication. Alterations in slow axonal transport observed following chronic acrylamide intoxication closely resemble those produced by axotomy (Hoffman and Lasek, 1980; Hoffman et al., 1984). The distance of transport for tubulin and actin were increased, as demonstrated by the greater amount of these polypeptides which moved with the faster $\mathrm{SCb}$ phase of transport. The spectrum of velocities (front, peak, tail) over which the neurofilaments were transported was not altered, although the curves suggested a faster overall rate because of the reduction in the height of the peak; normally, the peak occurs closer to the tail. The decrease in the relative amount of neurofilament triplet proteins suggests a reduction in perikaryal synthesis and/or delivery of neurofilament proteins to the axon. Our present results cannot differentiate between these two possibilities. Experiments are in progress to determine whether there is an alteration in synthesis of neurofilaments in dorsal root ganglia cells from chronic acrylamide-intoxicated rats.

The reduction in the amount of neurofilament proteins entering the axon is presumably the basis for the decreased amount of labeling in SCa in acrylamide neuropathy found by Sidenius and Jakobsen (1983). We believe these changes are due to neuronal response to acrylamide injury and represent a reordering of $\mathrm{SCb}$ synthesis and transport.

The proximal axonal atrophy found in the present study is also a feature of axotomized nerves (Gutmann and Sanders, 1943; Cragg and Thomas, 1961; Aitkin and Thomas, 1962; Carlson et al., 1979; Hoffman et al., 1984) and is the structural correlate of the decrease in the amount of neurofilament transport. Previous studies have established that axonal caliber is correlated with neurofilament content in normal nerves (Friede and Samorajski, 1970; Weiss and Mayr, 1971; Berthold, 1978). Recently, Hoffman et al. (1984) have demonstrated that the decrease in caliber following axotomy is correlated with neurofilament content. Axonal atrophy commences in the most proximal region of the axon and propagates distally with time, advancing down the nerve at the rate of slow transport and correlating with a decrease in neurofilament proteins entering axons. This change in caliber is reversible; when regenerating axons reach their target organs, the transport of neurofilament triplet proteins returns to normal, and axonal caliber is re-established (Kuno et al., 1974; Hoffman et al., 1984).

In a fashion similar to that observed following axotomy (Hoffman et al., 1984), the dorsal roots of experimental animals show reductions in axonal caliber. This atrophy was of greatest magnitude in regions nearest neuronal cell bodies. At the times examined, ventral roots did not change in caliber; this difference between sensory and motor fibers may reflect an earlier onset of axonal degeneration in sensory nerves (Schaumburg et al., 1974; Spencer and Schaumburg, 1974; Cavanagh, 1982). That these alterations in transport and caliber reflect secondary changes following distal axonal degeneration is supported by the finding at this time of degeneration of 

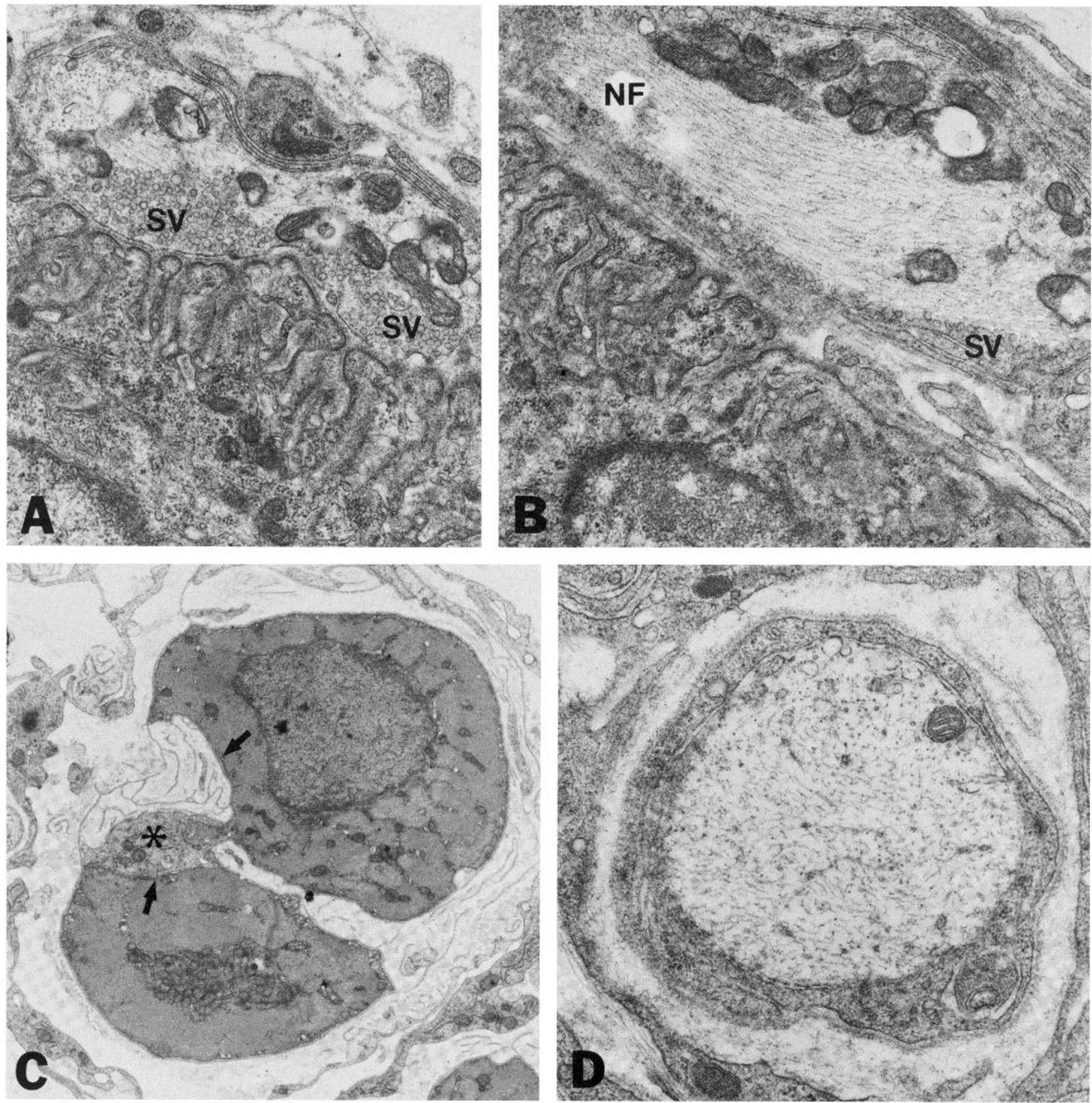

Figure 13. Electron micrographs of neuronal elements within the hindfeet of chronically acrylamide-intoxicated 7-week-old rats. $A$, Normal-appearing neuromuscular junction containing numerous synaptic vesicles (SV). Magnification $\times 23,770$. $B$, Degenerating neuromuscular junction. Note that the nerve terminal is retracted and contains many neurofilaments (NF); some synaptic vesicles (SV) are present within the terminal. Magnification $\times 24,150$. C, Equatorial region (note lymph space) of denervated muscle spindle showing loss of la afferent fibers. Note that indentation in the intrafusal nuclear bag muscle fibers (arrows) where la afferent terminals normally make synaptic contact; a phagocytic cell (asterisk) can be seen near one intrafusal fiber in regions once occupied by a nerve terminal. Magnification $\times 9,000$. D. Preterminal giant axonal swelling containing numerous neurofilaments as typically observed following chronic acrylamide administration (Prineas, 1969, Schaumburg et al., 1974). Magnification $\times 31,000$.

axons in la afferent and motor nerves. However, it is possible that these alterations in transport and caliber may arise prior to structural degeneration of the axon. A similar change in axonal caliber, determined electrophysiologically, has been observed following botulinum toxin (Stanley et al., 1984), a compound which prevents the vesicular release of transmitter at the neuromuscular junction without producing axonal degeneration.

Conclusion. Studies of acute and chronic acrylamide intoxication demonstrate quite divergent changes in transport and caliber and emphasize the close association between slow axonal transport, 
neurofilament content, and fiber caliber. In addition, these studies help to clarify some conflicts in the literature concerning the effects of acrylamide upon slow axonal transport. Our results are instructive, since they demonstrate that a toxic agent which results in distal axonal degeneration can reproduce some of the alterations in transport and caliber which follow axotomy. Finally, we suggest that light and ultrastructural morphometry of proximal regions of large axons can provide a simple means of screening agents for the capacity to impair neurofilament transport and produce neurofilamentous neuropathies.

\section{References}

Aitkin, J. T., and P. K. Thomas (1962) Retrograde changes in fibre size following nerve section. J. Anat. 96: 121-129.

Anthony, D. C., K. Boekelheide, and D. G. Graham (1983a) The effect of 3,4-dimethyl substitution on the neurotoxicity of 2,5-hexanedione. I. Accelerated clinical neuropathy is accompanied by more proximal swellings. Toxicol. Appl. Pharmacol. 72: 362-371.

Anthony, D. C., F. Giangaspero, and D. G. Graham. (1983b) The spatiotemporal pattern of the axonopathy associated with the neurotoxicity of 3,4-dimethyl-2,5-hexanedione in the rat. J. Neuropathol. Exp. Neurol. 42: 548-560.

Berthold, C. H. (1978) Morphology of normal peripheral axons. In Physiology and Pathobiology of Axons, S. G. Waxman, ed., pp. 3-63, Raven Press, New York

Bradley, W. G., and M. H. Williams (1973) Axoplasmic flow in axonal neuropathies. I. Axoplasmic flow in cats with toxic neuropathies. Brain 96: 235-246.

Carlson, J., A. C. Lais, and P. J. Dyck (1979) Axonal atrophy from permanent peripheral axotomy in adult cat. J. Neuropathol. Exp. Neurol. 38: 579-585.

Cavanagh, J. B. (1964) The significance of the "dying back" process in human and experimental neurological diseases. Int. Rev. Exp. Pathol. 3: 219-267.

Cavanagh, J. B. (1982) The pattern of recovery of axons in the nervous system of rats following 2,5-hexanediol intoxication: A question of rheology? Neuropathol. Appl. Neurobiol. 8: 19-34.

Cragg, B. G., and P. K. Thomas (1961) Changes in conduction velocity and fibre size proximal to peripheral nerve lesions. J. Physiol. (Lond.) 157: 315-327.

Friede, R. L., and T. Samorajski (1970) Axon caliber related to neurofilaments and microtubules in sciatic nerve fibers of rats and mice. Anat. Rec. 167: 379-388.

Fullerton, P. M., and J. M. Barnes (1966) Peripheral meuropathy in rats produced by acrylamide. Br. J. Ind. Med. 23: 210-221.

Gold B. G., J. W. Griftin, and D. L. Price (1983) Slow axonal transport following single high-dose acrylamide administration. Soc. Neurosci. Abstr. 9: 669.

Griffin, J. W., D. B. Drachman, and D. L. Price (1976) Fast axonal transport in motor nerve regeneration. J. Neurobiol. 7: 355-370.

Griffin, J. W., D. L. Price D. B. Drachman, and J. Morris (1981) Incorporation of axonally transported glycoproteins into axolemma during nerve regeneration. J. Cell Biol. 88: 205-214.

Griffin, J. W., L. C. Cork, P. N. Hoffman, and D. L. Price (1984) Experimental models of motor neuron degeneration. In Peripheral Neuropathy, P. J. Dyck, P. K. Thomas, E. H. Lambert, and R. Bunge, eds., Vol. I, pp. 621635 , W. B. Saunders Co., Philadelphia.

Gutmann, E., and F. K. Sanders (1943) Recovery of fibre numbers and diameters in the regeneration of peripheral nerves. J. Physiol. (Lond.) 101: 489-518.

Hoffman, P. N., and R. J. Lasek (1980) Axonal transport of the cytoskeleton in regenerating motor neurons: Constancy and change. Brain Res. 202: 317-33.

Hoffman, P. N., R. J. Lasek, J. W. Griffin, and D. L. Price (1983) Slowing of the axonal transport of neurofilament proleins during development. J. Neurosci. 3: 1694-1700.

Hoffman, P. N., J. W. Griffin, and D. L. Price (1984) Control of axonal caliber by neurofilament transport. J. Cell Biol. 99: 705-714.

Howland, R. D. (1981) The etiology of acrylamide neuropathy. Enolase, phospho-fructokinase 'and glyceraldehyde-3-phosphate dehydrogenase activities in peripheral nerves, spinal cord, brain, and skeletal muscles of acrylamide-intoxicated cats. Toxicol. Appl. Pharmacol. 60: 324-333.

Howland, R. D., I. L. Vyas, H. E. Lowndes, and T. M. Argentieri (1980) The etiology of toxic peripheral neuropathies: In vitro effects of acrylamide and 2,5-hexanedione on brain enolase and other glycolytic enzymes. Brain Res. 202: 131-142.

Jakobsen, J., and P. Sidenius (1983) Early and dose-dependent decrease of retrograde axonal transport in acrylamide-intoxicated rats. J. Neurochem. 40: 447-454.

Komiya, Y., and M. Kurokowa (1980) Preferential blockade of the tubulin transport of colchicine. Brain Res. 190: 505-516.

Kuno, M., Y. Miyata, and E. J. Munoz-Martinez (1974) Properties of fast and slow alpha motoneurones following motor reinnervation. J. Physiol. (Lond.) 242: 273-288.

Lasek, R. J., and P. N. Hoffman (1976) The neuronal cytoskeleton, axonal transport and axonal growth. Cold Spring Harbor Conf. Cell Proliferation 3: $1021-1049$.

Miller, M. S., M. J. Miller, T. F. Burks, and I. G. Sipes (1983) Altered retrograde axonal transport of nerve growth factor after single and repeated doses of acrylamide in the rat. Toxicol. Appl. Pharmacol. 69: 96-101.

Morris, J. R., and R. J. Lasek (1982) Stable polymers of the axonal cytoskeleton: The axoplasmic ghost. J. Cell Biol. 92: 192-198.

Morris, J. R., and R. J. Lasek (1984) Monomer-polymer equilibria in the axon: Direct measurement of tubulin and actin as polymer and monomer in axoplasm. J. Cell Biol. 98: 2064-2076.

Pleasure, D. E., K. C. Mishler, and W. K. Engel (1969) Axonal transport of proteins in experimental neuropathies. Science 166: 524-525.

Prineas, J. (1969) The pathogenesis of dying-back polyneuropathies. II. An ultrastructural study of experimental acrylamide intoxication in the cat. $\mathrm{J}$. Neuropathol. Exp. Neurol. 28: 598-621.

Roots, B. I. (1983) Neurofilament accumulation induced in synapses by leupeptin. Science 221: 971-972.

Sahenk, Z., and J. R. Mendell (1981) Acrylamide and 2,5-hexanedione neuropathies: Abnormal bidirectional transport rate in distal axons. Brain Res. 219: 397-405.

Schaumburg, H. H., M. Wisniewski, and P. S. Spencer (1974) Ultrastructural studies of the dying-back process. I. Peripheral nerve terminal and axon degeneration in systemic acrylamide intoxication. J. Neuropathol. Exp. Neurol. 33: 260-284.

Sickles, D. W., and B. D. Goldstein (1985) Acrylamide (ACR)-induced changes in metabolism and HRP transport in spinal neurons. Neurotoxicology, 5: 311 .

Sidenius, P., and J. Jakobsen (1983) Anterograde axonal transport in rats during intoxication with acrylamide. J. Neurochem. 40: 697-704.

Spencer, P. S., and H. H. Schaumburg (1974) A review of acrylamide neurotoxicity. II. Experimental animal neurotoxicity and pathologic mechanisms. Can. J. Neurol. Sci. 1: 152-169.

Spencer, P. S., and H. H. Schaumburg (1976) Central peripheral distal axonopathy-The pathology of dying-back polyneuropathies. In Progress in Neuropathology, H. M. Zimmerman, ed., Vol. III, pp. 253-295, Grune and Stratton, New York.

Spencer, P. S., and H. H. Schaumburg (1977) Uitrastructural studies of the dying-back process. III. The evolution of experimental peripheral giant axonal degeneration. J. Neuropathol. Exp. Neurol. 36: 276-299.

Spencer, P. S., M. I. Sabri, H. H. Schaumburg, and C. L. Moore (1979) Does a defect of energy metabolism in the nerve fiber underlie axonal degeneration in polyneuropathies? Ann. Neurol. 5: 501-507.

Stanley, E. F., P. N. Hoffman, J. W. Griffin, and D. L. Price (1984) Effect of axotomy on conduction in the proximal motor nerve. Neurology 34 (Supp/ 1): 182.

Sezuki, K., and L. D. Pfaff (1973) Acrylamide neuropathy in rats. An electron microscope study of degeneration and regeneration. Acta Neuropathol. (Berl.) 24: 193-213.

Weiss, P. A., and R. Mayr (1971) Organelles in neuroplasrric ("axonal") flow: Neurofilaments. Proc. Natl. Acad. Sci. U. S. A. 68: 846-850. 